\title{
LAS FAMILIAS MONOPARENTALES EN ESPAÑA ${ }^{1}$
}

\author{
Juan Antonio Fernández Cordón \\ Consejo Superior de Investigaciones Científicas
}

Constanza Tobío Soler

Universidad Carlos III de Madrid

\begin{abstract}
RESUMEN
El concepto de monoparentalidad adolece de una notable imprecisión al integrar situaciones muy diferentes como la viudedad, la procreación sin pareja y el divorcio o separación. El factor común a todas ellas es la carga de los hijos asumida por un único progenitor, lo cual obliga a definir el significado exacto de estos dos aspectos. El artículo presenta el análisis de la monoparentalidad en España realizado a partir de una explotación especial de datos del Censo de Población de 1991 y de la Encuesta de Población Activa de 1991 y 1996 según criterios comparativos con los adoptados en la mayor parte de los países europeos. Se aportan datos acerca de los núcleos familiares y de los hogares monoparentales y se analizan las características de las madres en situación de monoparentalidad según edad, nivel de estudios, actividad y paro.
\end{abstract}

\section{DELIMITACIÓN CONCEPTUAL Y OPERATIVIZACIÓN}

\section{Origen y evolución de un concepto impreciso}

El concepto de monoparentalidad aparece en los años setenta como crítica a la familia nuclear "parsoniana" en tanto que modelo de referencia y encarna-

${ }^{1}$ Los resultados que se presentan en este artículo proceden en gran parte de una investigación realizada mediante convenio entre el Ministerio de Trabajo y Asuntos Sociales y la Universidad Carlos III de Madrid sobre "Las familias monoparentales en España" (Fernández Cordón y Tobío, 1997). 
ción de la normalidad deseable. Tiene, así, un componente reivindicativo en cuanto a la aceptación social de otras formas de familias diferentes a la formada por una pareja conyugal con sus hijos. El término que ha acabado por imponerse en francés o en español: "familias monoparentales", es una traducción no demasiado afortunada de lone parent families, denominación que parece haberse impuesto en los países anglosajones frente a las menos precisas de single parent families o one parent families.

Siempre han existido a lo largo de la historia las situaciones hoy englobadas en el término de monoparentalidad (Reher, 1997: 148-160), la viudedad, la procreación fuera del matrimonio y las separaciones conyugales. Sin embargo, su consideración social era muy diferente, casi opuesta ${ }^{2}$. Las viudas frecuentemente han representado una feminidad casta, cercana a la de las religiosas, y disfrutaban de un elevado prestigio social quizá relacionado con su autonomía económica y personal; las madres solteras, en cambio, se asocian al desorden y al descontrol, casi a la prostitución. Los factores morales elevaban una barrera entre viudas y madres solteras que ocultaba sus rasgos comunes, la carga de los hijos en soledad. A ellas se añaden las separadas y divorciadas con hijos, que constituyen hoy la forma predominante de monoparentalidad.

La extensión del concepto de monoparentalidad en los últimos años se asocia también a la reivindicación de la normalidad de las familias no basadas en la conyugalidad, incluso de aquellas cuyo origen está en el rechazo a la biparentalidad, es decir, las mujeres — raramente los hombres - que desean tener hijos en soledad, sin una pareja. Pero el auge del concepto tiene que ver asimismo con la idea de la monoparentalidad como factor de riesgo de pobreza, de exclusión social y, en especial, de riesgo para los hijos. En este último sentido, la perspectiva nueva e integradora de diversos tipos de familia se superpone a un punto de vista anterior que asocia la monoparentalidad a una situación negativa, fuente de problemas y conflictos sociales en relación a aspectos como el fracaso escolar, el comportamiento familiar, la salud, la delincuencia o la movilidad social ${ }^{3}$. La consideración de la monoparentalidad como factor de riesgo está muy generalizada en los enfoques psicológicos, perspectiva en la que todavía es dominante este punto de vista, a pesar de que ha sido objeto de múltiples críticas, especialmente en Francia (Le Gall y Martin, 1987).

El debate teórico más reciente a propósito de la monoparentalidad se centra en la dinámica de estas situaciones, después de un período en el que domi-

2 Sin embargo, en algunos momentos históricos alejados en el tiempo el estatus de las mujeres que tenían hijos fuera del matrimonio era en algunos casos elevado; por ejemplo, en el de las concubinas cortesanas o campesinas del seńor feudal. Yvonne Knibiehler (1993) plantea que el período más represivo para las madres solteras transcurre entre los siglos XVI y XIX, iniciándose a partir del XX un lento proceso de liberalización.

${ }^{3}$ Entre otros, se pueden seńalar sobre temas educativos: Dronkers (1994), Neyrand (1990), Bank et al. (1993); comportamiento familiar: Kiernan (1992), Webster et al. (1995); situación económica: Thomson et al. (1994); salud: Judge et al. (1993); delincuencia: Rankin et al. (1994), o movilidad social: Bilarz et al. (1993). 
naron los estudios centrados en los aspectos psicológicos primero y en la situación económica de este tipo de familias después. Diversas investigaciones recientes (Martin, 1994; Duncan et al., 1994) muestran que una parte importante de la población experimenta a lo largo de su vida situaciones de monoparentalidad como hijo o como progenitor, pero que generalmente representan una fase de trayectorias en las que el individuo se integra en diferentes tipos de familia. Según la investigación longitudinal de Duncan, un tercio de los nacidos entre 1966 y 1975 ha vivido al menos durante un tiempo sólo con su madre antes de los 18 ańos (dos tercios en el caso de los de raza negra), pero la mayor parte lo ha hecho durante un período de tiempo corto y sólo uno de cada diez ha vivido toda su infancia solamente con su madre. Festy (1989) estima, a partir de una encuesta de 1985 para el caso francés, que el 85 por 100 de los hijos divorciados ha visto cómo su madre o su padre constituían una nueva pareja. En resumen, el concepto de monoparentalidad integra situaciones sociales viejas (viudas, madres solteras) y nuevas (divorcios), al tiempo que aparece a la vez como reivindicación de la legitimidad de una pluralidad de formas familiares y como una expresión de la vulnerabilidad de aquellas en las que falta uno de los progenitores. La relativa imprecisión del concepto, que diversos autores han puesto de manifiesto, puede justificarse por la emergencia reciente de la problemática que éste pretende expresar.

\section{El análisis empírico de la monoparentalidad}

A los problemas de precisión teórica de los conceptos se añaden los derivados de su operativización empírica, en especial cuando se intenta utilizar las fuentes de información básicas como los censos de población o las encuestas de población activa. El análisis empírico de la monoparentalidad supone clarificar o definir los dos aspectos principales que constituyen esa situación, el hecho de que hay un único progenitor y la carga o la dependencia de los hijos.

La inexistencia de pareja conviviente es una de las condiciones para que un hogar pueda ser considerado monoparental, aunque se ha discutido (Roll, 1992a) si una pareja conyugal cohabitante debe considerarse o no equivalente a un matrimonio. A pesar de las diferencias entre las parejas conyugales casadas y las de hecho, hay acuerdo en que las semejanzas son mayores que las diferencias, pero, en la práctica, la recogida de información sobre las parejas cohabitantes adolece de imperfecciones, lo que impide la identificación de algunas situaciones de monoparentalidad. También se plantea el problema contrario, cuando una pareja conyugal no convive porque cada uno de sus miembros habita en un hogar diferente.

El otro elemento que compone el concepto de monoparentalidad es la carga o la dependencia de los hijos. Para incluir únicamente los hijos dependientes, lo más frecuente es definir una edad por debajo de la cual se considera que todos lo son. En la mayor parte de los países se sitúa en los 18 ańos, pero 
en algunos es diferente, como en Francia, donde se considera a efectos censales que hasta los 25 años los hijos están a cargo de los padres. En España (como también en Bélgica, por ejemplo) el criterio que se utiliza es el del estado civil de los hijos.

La importación del concepto de monoparentalidad es muy reciente en España y se puede, además, datar con precisión. En 1987, Julio Iglesias de Ussel organizó con la colaboración del Instituto de la Mujer, el Centre National de la Recherche Scientifique (CNRS) de Francia y la CAYCIT del Ministerio de Educación e Investigación un encuentro internacional sobre las familias monoparentales en el que se abordó el tema desde una diversidad de puntos de vista, desde los más habituales (definiciones, tipos, cuestiones conceptuales, situación económica, políticas sociales) hasta otros menos frecuentes como las especificidades de la monoparentalidad en las cárceles o entre los emigrantes (Iglesias de Ussel, 1988). En el seminario y en el libro publicado posteriormente que recoge las ponencias presentadas se plantea de forma amplia y rigurosa una pluralidad de aspectos y de problemas en torno a la monoparentalidad, entre otros la definición operativa de la familia monoparental, proponiéndose ya entonces lo que hoy tiende a imponerse como definición estándar, "aquellas que incluyan un hijo con hasta 18 años en convivencia con su padre $o$ madre" (Iglesias de Ussel, 1988: 28). La información empírica para el caso español se basaba principalmente en los datos publicados de los Censos de Población, aunque señalando sus múltiples carencias y limitaciones para estudiar el fenómeno de la monoparentalidad (falta de continuidad de las series, retrasos en la publicación, falta de desagregación de los datos, etc.). Pero probablemente más sorprendente que las insuficiencias detectadas en 1987 sea el hecho de que ocho años después la situación siga siendo muy similar, tal como señalan Elisabet Almeda y Lluis Flaquer (1995). La realidad es que hasta ahora no ha sido posible determinar de forma fiable y equiparable a la información de los países de nuestro entorno ni siquiera el número de familias monoparentales.

El mayor problema que plantean las publicaciones oficiales basadas en la fuente principal, el Censo de Población, es que no se ajustan a la definición más aceptada de familia monoparental, puesto que los núcleos familiares incluyen todos los hijos solteros, cualquiera que sea su edad, tanto si son dependientes como si contribuyen a los recursos del hogar o si el dependiente es el padre o la madre.

No se puede, sin embargo, culpar exclusivamente al Instituto Nacional de Estadística (INE) de esta carencia informativa, puesto que no dispone en este caso de categorías claras y unánimemente aceptadas que pueda incluir en los cuadros que publica. El concepto de monoparentalidad, de reciente aparición, adolece todavía de un grado de imprecisión notable entre los sociólogos de la familia y entre los demógrafos. De ahí que los países de nuestro entorno produzcan estadísticas de contenido diverso, difícilmente comparables las unas con las otras, y que muchas de las publicaciones recientes estén todavía centradas en problemas de medición. 
En la realidad, en Espańa, las dificultades anteriores sólo afectan a los datos publicados por el INE, ya que, por ejemplo, la información contenida en el Censo de Población de 1991, excepcionalmente rica en lo referido a las estructuras familiares, permite conocer de forma adecuada y pormenorizada el número y las características de las familias monoparentales. Para ello se requieren explotaciones específicas, y éstas plantean la necesidad de acotar con precisión los conceptos utilizados.

En el Censo, el núcleo familiar constituye una unidad básica formada por una pareja, con o sin hijos, o por una persona con al menos un hijo. Plantea un problema de frontera el caso de los hijos: ¿̨hasta cuándo un hijo es una persona dependiente y debe, por tanto, ser considerado como miembro del núcleo? En las estadísticas del INE, el criterio es muy amplio: figuran en el núcleo familiar todos los hijos solteros, sin consideración de su edad. Es cierto que la tendencia reciente de emancipación tardía de los hijos puede añadir justificación a este criterio, pero, en el caso de los hijos mayores, no se trata de una convivencia equiparable a la que une a miembros de una pareja o la que afecta a hijos pequeños, puesto que intervienen en mayor medida determinantes externos cambiantes, como la duración de la escolaridad, la situación del mercado de trabajo y valoraciones culturales de la propia permanencia en la familia, también cambiantes. La dependencia de los hijos sólo escapa a la voluntad de los interesados y de sus padres hasta que los primeros cumplen 16 años, mientras la ley les impide trabajar y les deja, salvo en casos muy excepcionales, a cargo de sus padres. La mayoría de edad, fijada a los 18 años, es también otro requisito para el pleno ejercicio de sus derechos por los hijos.

La convivencia de hijos mayores con sus padres, especialmente con un solo padre, puede encubrir una situación de dependencia inversa, de los padres hacia los hijos, tanto más frecuente cuanto los hijos son más mayores. La definición del Censo no permite distinguir entre estos dos tipos de dependencia, aunque la frecuencia de núcleos con padres dependientes es, sin duda, reducida al incluir únicamente a hijos solteros: la situación de una madre que vive a cargo de su hijo o hija casado, aunque sea ella la que figure como persona principal en el Censo, ni siquiera sería recogida como núcleo familiar y sólo se observaría en el ámbito del hogar.

El criterio de incluir únicamente los hijos menores de 18 años, además de ser el más adecuado para efectuar comparaciones internacionales, responde a una lógica conceptual, al existir al menos una dependencia jurídica, y también a una lógica empírica, en la medida en que la casi totalidad de los hijos menores de 18 ańos son inactivos que siguen viviendo con sus padres. Éste es también el criterio utilizado para fijar un límite a algunas prestaciones sociales, en particular para la percepción de las ayudas familiares por hijo a cargo.

Uno de los rasgos que caracterizan la evolución reciente es la creciente importancia de los llamados "cohabitantes" o parejas de hecho (expresión esta última que parece haber sido adoptada en España), personas que viven en pareja sin estar legalmente casados. Hablar de madre o padre sin pareja no es 
ya, o es cada vez menos, equivalente a hablar de madre o padre no casado. También pueden darse casos de personas casadas que no viven en pareja. En España, ninguna de estas dos situaciones es todavía muy frecuente.

Las estadísticas no siempre recogen las situaciones de hecho, en cuyo caso las parejas no matrimoniales con hijos figuran como monoparentales (falsas monoparentales). Aunque éste no es el caso del Censo de 1991, no se descarta que en él se subestime su número. En todo caso, el tratamiento de este problema según los países debe ser evaluado a la hora de comparar los unos con los otros.

\section{Hogares y familias monoparentales}

Hogares monoparentales y familias monoparentales se consideran expresiones intercambiables, o al menos es lo que puede deducirse de su uso más frecuente. Esta confusión ha sido ya criticada (Durán, 1988) y merece la pena argumentar a favor de una terminología más rigurosa.

El término familia encubre una realidad difícil de estudiar empíricamente y es por tanto más impreciso, oponiéndose la evidencia intuitiva de su conocimiento a la dificultad de definir con precisión su extensión. Los franceses llaman red familiar (réseau familial) al conjunto de personas emparentadas que mantienen relaciones, de carácter económico o simplemente afectivo, y que funciona como sistema de solidaridad. Esta definición de la "familia", que corresponde al grupo de parentesco, sería la más próxima al concepto ordinario que manejamos en nuestra vida cotidiana, pero no concuerda con el concepto de familia en el Censo de Población, por ejemplo, o en otras encuestas. Hasta el Censo anterior de 1981, la llamada "familia censal" incluía a todos los que comparten la misma vivienda. En el Censo de 1991, el INE adopta plenamente las recomendaciones de Naciones Unidas sobre elaboración de censos de población y trata como familia al "grupo de personas (dos o más) que, residiendo en la misma vivienda familiar, comparten algunos gastos y están vinculados por lazos de parentesco, ya sean de sangre o políticos e independientemente de su grado" (INE, 1990: 28). Esta definición operativa de la familia también se aleja de la realidad social. Si en algún momento del pasado era habitual la convivencia de lo que se ha llamado la "familia extendida", la norma actual es que los hijos al casarse, o incluso antes, abandonen el hogar paterno, y se ha reducido muy considerablemente la coincidencia de núcleos familiares de varias generaciones en una misma vivienda. Ni siquiera el retraso actual de la emancipación de los jóvenes rompe este esquema, porque retrasan también la formación de su propio núcleo ${ }^{4}$. Los miembros de la familia actual viven cada vez más en viviendas separadas, lo cual no impide, tal como muestran las entrevistas realizadas a

${ }^{4}$ Entre 1986 y 1994, el porcentaje de jóvenes entre 25 y 30 ańos que permanecen en casa de sus padres ha pasado en Espańa del 53 al 65 por 100 (Fernández Cordón, 1997). 
mujeres monoparentales en el marco de esta investigación, que sigan manteniendo entre ellos relaciones de solidaridad afectiva y económica, en muchos casos de gran intensidad. Esta complejidad de la red familiar escapa totalmente a un instrumento como el Censo y queda para encuestas más limitadas y más especializadas.

De lo anterior se deduce que la expresión "familias monoparentales» es, sin duda, la manera menos adecuada de nombrar al tipo de unidad estudiado aquí. Si nos situamos en el ámbito de la familia en su sentido amplio, sólo podrían calificarse de monoparentales las de viudos; en las otras existen dos padres, aunque no convivan. Los hijos que viven con su madre separada tienen un padre y, generalmente, mantienen relaciones con él. Del análisis cualitativo que forma parte de esta investigación se deriva que también la madre puede recibir ayuda del cónyuge del que está separada y, en algunos casos, se establece incluso un reparto de tareas, compatible con la no convivencia.

En ese sentido, sería preferible hablar de núcleos familiares monoparentales (o núcleos monoparentales) porque el término designa sin ambigüedad el conjunto que forman un padre (o padre) con su o sus hijos que, fijando 18 años como edad límite, conviven prácticamente siempre con uno de los dos padres. No tendría, sin embargo, mucho sentido pretender ahora alterar prácticas lingüísticas bien implantadas, en España y en otros países, sobre todo cuando no existe ambigüedad manifiesta en lo que se nombra. Por ello, seguiremos utilizando como indistintas las dos expresiones: núcleo familiar monoparental (o simplemente núcleo monoparental) y familia monoparental.

El otro concepto, que aparece casi confundido con el de familia, es el de hogar. El hogar se concibe fundamentalmente como una unidad de convivencia en la que se organiza una solidaridad económica primaria. El Censo de 1991 lo define, siguiendo las recomendaciones internacionales, como "conjunto de personas que, residiendo en la misma vivienda, comparten gastos ocasionados por el uso de la vivienda y/o gastos de alimentación" (INE, 1990: 28). Los hogares pueden ser unipersonales o pluripersonales, formados éstos por personas emparentadas o no, y forman parte del hogar las personas del servicio doméstico y los huéspedes fijos.

De acuerdo con esta definición, hay mucha coincidencia entre los conceptos censales de "familia" $y$ "hogar». Existen hogares sin familia, los unipersonales y los formados por personas sin parentesco, y en los otros la familia es simplemente un subconjunto del hogar, el que forman las personas emparentadas entre sí.

A pesar de esta coincidencia parcial, lo importante es que el concepto de hogar introduce una lógica distinta. El núcleo familiar como forma histórica de organización de la reproducción obedece a una lógica principalmente demográfica y la convivencia viene impuesta por esa lógica. Por el contrario, en el hogar, como unidad de organización económica elemental, lo fundamental es la puesta en común de los recursos materiales y humanos de sus miembros.

Desde este punto de vista, lo importante es si el núcleo monoparental con- 
vive o no con otras personas, formando el conjunto un hogar. De ahí que la expresión "hogar monoparental" puede referirse a realidades muy distintas: un hogar formado exclusivamente por un núcleo monoparental o un hogar en el que, además de otras personas o de otros núcleos, se encuentra un núcleo monoparental. Sólo la primera acepción merece ser distinguida claramente porque representa una categoría de hogar específica, en relación a la puesta en común de recursos materiales y humanos, muy diferente, por ejemplo, de la pareja con hijos que también forme un hogar sin ninguna otra persona.

\section{LA INCIDENCIA DE LA MONOPARENTALIDAD EN ESPAÑA}

Conocer la incidencia real de la monoparentalidad en España —cuál es el número de familias monoparentales y cuáles son sus principales características - es un interrogante que lleva diez años planteado, sin que se le haya aportado una respuesta definitiva que permita, superada esta primera etapa del conocimiento, ahondar con mayor eficacia en el análisis sociológico propiamente dicho.

La fuente principal para el análisis de las familias monoparentales son los Censos de Población, y en particular, por las razones ya apuntadas, el realizado en 1991. Después de los Censos, la fuente estadística que más información puede aportar sobre la monoparentalidad es la Encuesta de Población Activa (EPA). Ésta tiene la ventaja de su constante actualización al realizarse cada tres meses, pero tiene como desventaja el hecho de que no está enfocada al análisis de estructuras y tipos familiares. El Ministerio de Asuntos Sociales ha realizado algunas explotaciones especiales, utilizando en ellas la definición más adecuada -madres o padres con algún hijo a cargo menor de 18 años.

En los últimos años se han realizado varias encuestas que proporcionan alguna información adicional sobre la monoparentalidad en España. La Encuesta sobre Desigualdad Familiar y Doméstica de 1984, dirigida por María Ángeles Durán, estima un 5 por 100 de hogares monoparentales, incluyendo todos aquellos en los que conviven un progenitor y sus hijos (Durán, 1988). La Encuesta sobre Condiciones de Vida y Trabajo de las Mujeres de 1985, del CIS, aporta datos sobre el estado civil de las madres solas que muestran que el grupo mayoritario dentro de este conjunto son las viudas (61 por 100) (Almeda y Flaquer, 1995). La Encuesta sobre Familia y Uso del Tiempo, del CIRES, también da alguna información sobre familias monoparentales constituidas a partir de una pareja rota (viudedad, separación o divorcio) en relación a su perfil socioeconómico, lugar de residencia y número de hijos menores de 18 años que conviven (Ministerio de Asuntos Sociales, 1995).

Recientemente se han publicado también algunas monografías sobre temas relacionados con la monoparentalidad en algunas comunidades españolas como Galicia (Hernández Rodríguez, 1996) o Asturias (Arenas Martínez, 1996), zonas en las que tradicionalmente las diversas formas de monoparenta- 
lidad han tenido una especial incidencia por diversas razones demográficas, económicas y culturales.

Todo este conjunto de fuentes contiene estimaciones diversas, con frecuencia no comparables entre ellas y en ocasiones contradictorias. El objetivo del presente análisis es suplir a lo que puede considerarse como una carencia importante, ofreciendo una información detallada, basada principalmente en una explotación específica de los datos del Censo de 1991, realizada sobre una muestra del 5 por 100 de hogares, facilitada por el INE, completada con algunas explotaciones específicas de la EPA. Siguiendo la práctica internacional más extendida y la explícita recomendación de algunos especialistas españoles (ver, por ejemplo, Iglesias de Ussel, 1988), se ha adoptado, como requisito básico para considerar que se trata de un núcleo monoparental, la presencia de al menos un hijo menor de 18 años, junto a una madre o un padre sin pareja, cualquiera que sea su estado civil, excluyendo las parejas de hecho e incluyendo a los casados que ya no viven juntos 5 .

Este trabajo, en el que se han tratado sobre todo los aspectos más cuantitativos del problema, se enmarca en un proyecto de investigación más amplio centrado en las estrategias de conciliación entre el trabajo remunerado y el cuidado de los hijos.

\section{¿Cuántas familias monoparentales?}

Los algo más de diez millones de núcleos familiares que forman la población española que vive en familia ${ }^{6}$ están constituidos, en su inmensa mayoría (casi el 87 por 100), de parejas formadas por dos personas casadas ${ }^{7}$. Hay sólo 222,7 mil parejas "de hecho" (aquellas en las que al menos uno de los miembros no está casado), lo que supone una incidencia muy pequeña (el 2,2 por 100 del total de núcleos), y existen 1.139 miles de núcleos de un padre, o una madre, sin pareja, con su o sus hijos (11,1 por 100 del total de núcleos).

En 7,8 millones de núcleos (algo más del 75 por 100) vive algún hijo, y en algo más de cinco millones, el hijo menor no ha cumplido 18 años. Entre éstos se encuentran los 454 mil núcleos monoparentales, en sentido estricto, que representan apenas el 40 por 100 del conjunto de núcleos formados por un padre o una madre con hijos pero sin pareja.

La inmensa mayoría (el 85 por 100) de los núcleos monoparentales los encabeza una mujer. Incluso si se incluyen los núcleos con hijos de cualquier

5 Se trata de la definición que propone Roll (1992), basada en la del informe de la CE «One Parent Families and Poverty in the EEC" (V/2541/2/82), aunque sustituyendo el concepto de "hijo dependiente" por la existencia de al menos un hijo de menos de 18 años, completada por nosotros con la consideración de la situación real de pareja, con independencia del estado civil.

${ }^{6}$ Excluida la población que vive en establecimientos colectivos.

7 Se supone que dos personas casadas que conviven como pareja están casadas entre ellas, aunque esto puede no ser cierto en algunos casos. 
edad, la proporción de mujeres sigue siendo prácticamente la misma (83 por 100). Se trata de una característica propia de este tipo de situación, que se da con intensidad comparable en todos los países de nuestro entorno (Roll, 1992b; European Observatory on National Family Policies, 1996).

La medida más adecuada de la incidencia de la monoparentalidad viene dada por la proporción que los núcleos monoparentales representan en el total de núcleos con hijo (parejas y monoparentales). Los núcleos de hijos de cualquier edad con un solo progenitor representan el 14,6 por 100 de todos los núcleos con hijo, 12,4 por 100 corresponden a los núcleos de madre sola y 2,8 por 100 a los de padre solo. Los núcleos monoparentales en sentido estricto, con algún hijo menor de 18 años, suponen el 8,6 por 100 del conjunto de núcleos con al menos un hijo de esa edad, de los cuales el 7,4 por 100 son monoparentales de madre y el 1,4 por 100 de padre. Finalmente, los núcleos monoparentales con algún hijo menor de 6 años representan el 5,5 por 100 de los núcleos con algún hijo a cargo de esta edad (cuadros $1 a$ y $1 b$ ).

La comparación con otros países se enfrenta con la dificultad de la diversidad de las definiciones, tanto en lo que se refiere a la edad del hijo menor como a la definición de las parejas. El cuadro 2 recoge los datos provenientes de los Censos de Población de ocho países en los que el límite de edad de los hijos está fijado en 18 años. De estos países, España es el que tiene la menor proporción de núcleos monoparentales.

El Censo español de 1991 permite detectar el conjunto de núcleos familiares que conviven en un mismo hogar, gracias a la introducción de preguntas sobre la relación de parentesco con otros miembros del hogar y no sólo con la persona principal. Se puede, por consiguiente, distinguir entre el núcleo principal, en el que figura la persona principal, y los núcleos secundarios del hogar, aunque ello no entrañe más jerarquía que la que se deriva de la designación de uno de los miembros como persona principal. Esta distinción es especialmente importante para la estimación de las situaciones de monoparentalidad en los jóvenes que conviven con sus padres. La mayoría de los Censos de otros países no permiten detectar los núcleos secundarios con el mismo detalle, y tampoco lo permiten otras fuentes como la Encuesta de Población Activa (EPA), que también se ha venido utilizando para estimar el número de monoparentales.

La incidencia de la monoparentalidad varía mucho según se tomen todos los núcleos ( $454 \mathrm{mil})$ o solamente los principales $(350 \mathrm{mil})$, puesto que el 42 por 100 de los núcleos secundarios con hijo son monoparentales. La proporción de monoparentales entre núcleos con hijos baja del 8,6 por 100 , cuando se considera el conjunto de núcleos, al 6,9 por 100 si se toman sólo los núcleos principales 


\section{CUADRO $1 a$}

Núcleos familiares, según categoría de núcleo y forma de convivencia. España, 1991. Conjunto de núcleos (Número de personas)

\begin{tabular}{|c|c|c|c|c|c|c|c|}
\hline \multirow[b]{3}{*}{$\begin{array}{l}\text { Categoria de núcleo } \\
\text { según edad del hijo menor }\end{array}$} & \multicolumn{6}{|c|}{ Forma de convivencia } & \multirow[b]{3}{*}{ Total núcleos } \\
\hline & \multicolumn{3}{|c|}{ Con pareja } & \multicolumn{3}{|c|}{ Sin pareja } & \\
\hline & $\begin{array}{l}\text { Parejas } \\
\text { casadas }\end{array}$ & $\begin{array}{l}\text { Parejas } \\
\text { de hecho }\end{array}$ & $\begin{array}{c}\text { Total núcleos } \\
\text { de pareja }\end{array}$ & $\begin{array}{c}\text { Madres } \\
\text { sin pareja }\end{array}$ & $\begin{array}{c}\text { Padres } \\
\text { sin pareja }\end{array}$ & $\begin{array}{l}\text { Total núcleos } \\
\text { sin pareja }\end{array}$ & \\
\hline Núcleos con algún hijo menor de 18 ............ & 4.743 .410 & 108.064 & 4.851 .474 & 385.269 & 69.293 & 454.562 & 5.306 .036 \\
\hline Núcleos con algún hijo menor de $6 \ldots \ldots \ldots \ldots \ldots . . . .$. & 1.835 .382 & 62.117 & 1.897 .498 & 110.361 & 19.372 & 129.733 & 2.027 .232 \\
\hline Núcleos con hijos, de cualquier edad ............... & 6.545 .359 & 122.119 & 6.667 .479 & 945.133 & 194.017 & 1.139 .150 & 7.806 .629 \\
\hline 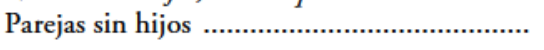 & 2.401 .482 & 100.654 & 2.502 .137 & & & & 2.502 .137 \\
\hline 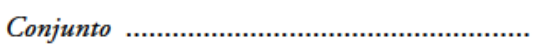 & 8.946 .842 & 222.773 & 9.169 .615 & 945.133 & 194.017 & 1.139 .150 & 10.308 .765 \\
\hline
\end{tabular}

FUENTE: Elaboración propia a partir de una muestra del 5 por 100 de hogares del Censo de 1991 (INE). 


\section{CUADRO $1 b$}

Distribución de los núcleos familiares, según categoría de núcleo y forma de convivencia. España, 1991. Conjunto de núcleos (Por cien de cada categoría de núcleo)

\begin{tabular}{|c|c|c|c|c|c|c|c|}
\hline \multirow[b]{3}{*}{$\begin{array}{l}\text { Categoria de núcleo } \\
\text { según edad del hijo menor }\end{array}$} & \multicolumn{6}{|c|}{ Forma de convivencia } & \multirow[b]{3}{*}{ Total núcleos } \\
\hline & \multicolumn{3}{|c|}{ Con pareja } & \multicolumn{3}{|c|}{ Sin pareja } & \\
\hline & $\begin{array}{l}\text { Parejas } \\
\text { casadas }\end{array}$ & $\begin{array}{l}\text { Parejas } \\
\text { de hecho }\end{array}$ & $\begin{array}{l}\text { Total núcleos } \\
\text { de pareja }\end{array}$ & $\begin{array}{l}\text { Madres } \\
\text { sin pareja }\end{array}$ & $\begin{array}{l}\text { Padres } \\
\text { sin pareja }\end{array}$ & $\begin{array}{l}\text { Total núcleos } \\
\text { sin pareja }\end{array}$ & \\
\hline Núcleos con algún hijo menor de 18 ............. & 89,4 & 2,0 & 91,4 & 7,3 & 1,3 & 8,6 & 100,0 \\
\hline Núcleos con algún hijo menor de 6 .................. & 90,5 & 3,1 & 93,6 & 5,4 & 1,0 & 6,4 & 100,0 \\
\hline Núcleos con hijos, de cualquier edad ................ & 83,8 & 1,6 & 85,4 & 12,1 & 2,5 & 14,6 & 100,0 \\
\hline 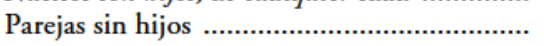 & 96,0 & 4,0 & 100,0 & & & & 100,0 \\
\hline 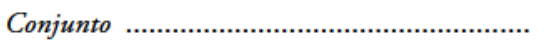 & 86,8 & 2,2 & 88,9 & 9,2 & 1,9 & 11,1 & 100,0 \\
\hline
\end{tabular}

FUENTE: Elaboración propia a partir de una muestra del 5 por 100 de hogares del Censo de 1991 (INE). 


\section{CUADRO 2}

Familias monoparentales en algunos países

(Porcentaje sobre el total de familias con algún hijo menor de 18 años)

\begin{tabular}{|c|c|c|}
\hline Pais & Año & Porcentaje \\
\hline 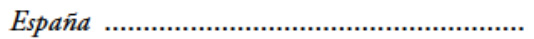 & 1991 & 8,6 \\
\hline 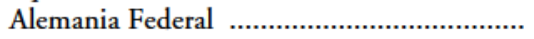 & 1989 & 15,7 \\
\hline 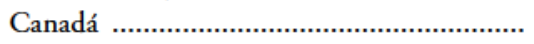 & 1991 & 16,8 \\
\hline 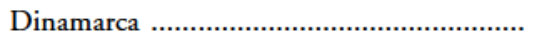 & 1990 & 22,0 \\
\hline 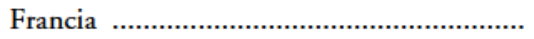 & 1990 & 11,9 \\
\hline 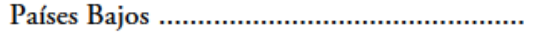 & 1988 & 18,1 \\
\hline 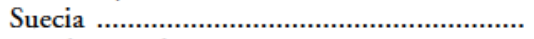 & 1990 & 22,3 \\
\hline 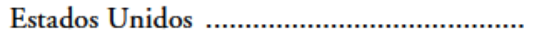 & 1989 & 23,5 \\
\hline
\end{tabular}

FUENTE: INSEE, Les familles monoparentales, INSEE, París, 1994.

\section{El estado civil: una distinción fundamental}

Como otras formas de la creciente diversificación del modelo familiar, la monoparentalidad no aparece como una vía alternativa frente a otros modelos posibles de convivencia más tradicionales. La diversidad familiar es más bien el resultado de una diversificación de las trayectorias familiares de las personas, que se van alejando del modelo tradicional de ciclo de vida (antes basado en la secuencia noviazgo - matrimonio - nacimientos - emancipación de los hijos «nido vacío» - viudez).

Hoy, el núcleo monoparental es casi siempre el resultado de la ruptura de una unión anterior, por la muerte del cónyuge, en el caso de los viudos, o por separación o divorcio, y constituye una consecuencia indirecta, un subproducto, de la ruptura. Sólo entre los solteros con hijos, la monoparentalidad podría reflejar una opción de vida, aunque en la práctica esta situación se nutre sobre todo de concepciones prematrimoniales, en la mayoría de los casos no deseadas (especialmente entre las adolescentes), o es el resultado de la ruptura de una pareja de hecho.

Distinguir los núcleos monoparentales según el estado civil del progenitor es, por tanto, algo más que clasificarlos según una característica entre otras. Contribuye a clarificar tanto el análisis de las causas que generan las diversas situaciones de monoparentalidad como el de las diferencias que encubre la unificación de situaciones muy dispares en un concepto único. Las familias monoparentales de solteros, de separados y divorciados o de viudos representan etapas de trayectorias bien diferenciadas y presentan rasgos específicos.

La mayoría (el 52,7 por 100) de los núcleos monoparentales la forman per- 
sonas separadas o divorciadas (incluyendo las separadas de hecho ${ }^{8}$ ): el 52,1 por 100 de las madres y el 56 por 100 de los padres sin pareja están en esa situación (cuadro 3). Los viudos representan el 27,6 por 100 del conjunto de monoparentales, siendo mayor la proporción de hombres $(33,1$ por 100$)$ que la de mujeres (26,8 por 100$)$. La proporción de solteros, que no llega al 20 por 100 de los monoparentales, alcanza entre las madres el doble de la de los padres ( 21,3 y 10,9 por 100 , respectivamente).

\section{CUADRO 3}

Distribución de los núcleos monoparentales, según el tipo de núcleo. España, 1991 (En porcentaje)

\begin{tabular}{|c|c|c|c|}
\hline \multirow[b]{2}{*}{ Tipo de monoparental } & \multicolumn{3}{|c|}{ Hijo menor de 18 años } \\
\hline & Madres & Padres & Conjunto \\
\hline Solteros ............... & 21,3 & 10,9 & 19,7 \\
\hline 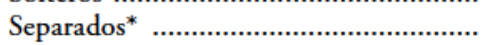 & 52,1 & 56,0 & 52,7 \\
\hline 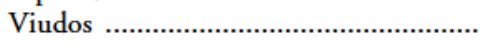 & 26,6 & 33,1 & 27,6 \\
\hline \multirow[t]{2}{*}{ 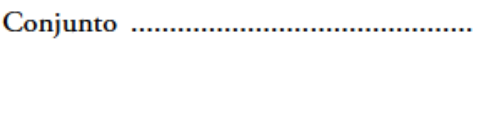 } & 100,0 & 100,0 & 100,0 \\
\hline & \multicolumn{3}{|c|}{ Hijo menor de 6 años } \\
\hline Solteros & 38,2 & 22,0 & 35,8 \\
\hline Separados* & 53,6 & 68,9 & 55,9 \\
\hline 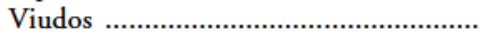 & 8,2 & 9,1 & 8,3 \\
\hline \multirow[t]{2}{*}{ 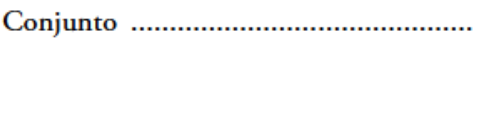 } & 100,0 & 100,0 & 100,0 \\
\hline & \multicolumn{3}{|c|}{ Hijo de cualquier edad } \\
\hline Solteros & 10,7 & 5,1 & 9,8 \\
\hline 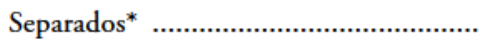 & 28,2 & 29,7 & 28,4 \\
\hline 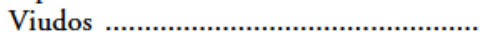 & 61,1 & 65,2 & 61,8 \\
\hline 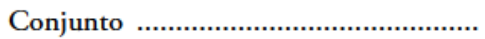 & 100,0 & 100,0 & 100,0 \\
\hline
\end{tabular}

* Incluye divorciados, legalmente separados y separados de hecho.

FUENTE: Elaboración propia a partir de una muestra del 5 por 100 de hogares del Censo de 1991 (INE).

El límite de edad fijado para determinar la inclusión de un hijo a cargo afecta notablemente la distribución de los núcleos monoparentales entre estas tres categorías: cuanto más alto es el límite, mayor es la proporción de viudos.

${ }^{8}$ Personas casadas que no conviven con su cónyuge. 
Éstos constituyen casi dos tercios de los núcleos sin pareja con hijo de cualquier edad: el 62 por 100 del conjunto, el 65 por 100 de los padres y el 61 por 100 de las madres. Por el contrario, entre las familias monoparentales con hijo a cargo menor de 6 años abundan las madres solteras (el 38 por 100, muy por encima del conjunto de las monoparentales) y las separadas o divorciadas $(53,6$ por 100), mientras que el porcentaje de viudas o viudos es muy reducido, reflejo de la menor probabilidad de enviudar a las edades en que se tienen hijos pequeños. Los padres con hijo de menos de 6 años son sobre todo separados o divorciados (más de dos tercios), aunque el porcentaje de solteros (22 por 100) es también mucho más elevado que en el conjunto de monoparentales.

La evolución más reciente sólo se puede analizar con ayuda de la EPA. La comparación directa de los datos de la EPA del 2..$^{\circ}$ trimestre de 1991 y de 1995 muestra un ligerísimo aumento del número total de núcleos monoparentales, pero es necesario tener en cuenta que esta fuente subestima y distorsiona la incidencia de la monoparentalidad. El principal problema es que no detecta los núcleos secundarios, formados en una alta proporción por madres jóvenes que conviven con sus propios padres. También se observan discrepancias con el Censo en la distribución por edades y estado civil y en la proporción de monoparentales en cada estado. Para mejorar la comparación, se han corregido los datos de la EPA de 1991 y 1995 ( $2 .^{\circ}$ trimestre en cada caso), utilizando la distribución por edades del Censo de 1991, y de la proyección de población realizada por el INE para 1995 y aplicando proporciones de monoparentales por edad y estado civil corregidas para tener en cuenta el porcentaje de subestimación de la EPA de 1991 en relación al Censo del mismo año.

La comparación con los datos corregidos pone de manifiesto una ligera disminución del número de monoparentales, equivalente en la práctica al mantenimiento de su número, pero como durante el mismo período disminuye significativamente el número de parejas con hijo menor de 18 años, el resultado es un incremento de la proporción de núcleos monoparentales en el conjunto de núcleos con hijo a cargo.

Entre 1991 y 1995 disminuye el número de madres solteras, a pesar del aumento del número de mujeres que permanecen solteras, en consonancia con la disminución de la fecundidad de los jóvenes y el retraso de su emancipación. También disminuye el número de viudas con hijo menor a cargo, aunque el número total de viudas se mantiene. Finalmente, a pesar del incremento considerable del número de separadas y divorciadas, no aumenta el número de las que tienen hijo a cargo. Con todo, el peso relativo de las monoparentales separadas o divorciadas sube del 52 al 55 por 100.

Estas tendencias coinciden en lo fundamental con lo observado en otros países hace unos años (ver, por ejemplo, para Francia, Martin, 1995) y puede considerarse, por tanto, que reflejan sustancialmente la realidad.

En resumen, la monoparentalidad tiene en España una incidencia relativamente pequeńa, situándose por debajo de un país como Francia y muy por debajo de los países nórdicos de Europa o de Estados Unidos. En los últimos 
años, la proporción de familias monoparentales ha aumentado moderadamente. Lo más significativo ha sido el cambio de composición interna, con un peso creciente de las madres divorciadas y separadas y una disminución del de las madres solteras.

\section{Autonomía o dependencia: los hogares monoparentales}

El hogar constituye la unidad fundamental de convivencia, en la que se ponen en común los recursos de sus miembros y se establece una unidad doméstica de gasto, generadora de economías de escala, que lo justifica desde un punto de vista estrictamente económico. Los recursos puestos en común incluyen, además de los monetarios, la capacidad de servicio y de cuidados mutuos $^{9}$ de los componentes del hogar. El núcleo familiar monoparental, compuesto de un padre o una madre con sus hijos, tiene una situación muy distinta, desde estos dos puntos de vista, según que comparta el hogar con otras personas o que deba valerse por sí mismo. Menores economías de escala y menores ingresos provocan, en la mayoría de los casos, la fragilidad económica de los hogares monoparentales (aquellos formados únicamente por el núcleo monoparental). La pareja cuenta con la capacidad de trabajo doméstico de uno de los dos (generalmente la mujer), cuando existe un único perceptor, o con un ingreso adicional si los dos trabajan. En el hogar monoparental la percepción de una pensión, no siempre existente, no puede equipararse al ingreso adicional del cónyuge, y la generalmente necesaria obtención de un ingreso derivado de la actividad laboral moviliza a la madre, dificultando el cuidado de sus hijos y obligándole a desarrollar estrategias específicas.

Estas circunstancias explican que más del 40 por 100 de los núcleos monoparentales vivan en un hogar con otras personas que no forman parte del núcleo, una proporción muy superior a la de los núcleos de parejas, que es del 14 por 100 (cuadro 4). Existen 271 miles de hogares monoparentales propiamente dichos (el 6,1 por 100 del total de hogares de un solo núcleo), de los cuales 228,5 miles lo son de madres (el 85 por 100) y 42,5 miles de padres ( 15 por 100).

La autonomía de las familias monoparentales es mucho mayor cuando éstas proceden de una unión anterior: las viudas (76 por 100) y las separadas (64 por 100), mientras sólo una minoría de las madres solteras (28 por 100) vive en un hogar independiente.

Para valorar correctamente estas cifras es necesario tener en cuenta las grandes diferencias de edad que separan a las diversas categorías de monoparentales, ya que el hecho de formar un hogar independiente varía significativamente con la edad. Cualquiera que sea el tipo de monoparental, la proporción que vive sin personas externas al núcleo es baja en las edades más jóvenes y

9 Lo que se entiende por el concepto de caring capacity en inglés. 


\section{CUADRO 4}

Distribución de los núcleos familiares, según el tipo de núcleo y el tipo de hogar. España, 1991. Madres con algún hijo menor de 18 años

(Tipos de hogar por cien de cada tipo de núcleo)

\begin{tabular}{|c|c|c|c|c|c|c|}
\hline \multirow[b]{3}{*}{ Tipo de hogar } & \multicolumn{5}{|c|}{ Tipo de núcleo } & \multirow[b]{3}{*}{ Total } \\
\hline & \multirow[b]{2}{*}{ Pareja } & \multicolumn{4}{|c|}{ Monoparentales } & \\
\hline & & Soltera & Separada & Viuda & Conjunto & \\
\hline 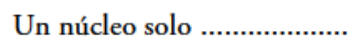 & 85,9 & 27,9 & 63,8 & 75,7 & 59,3 & 83,9 \\
\hline Núcleo con otros ...................... & 14,1 & 72,1 & 36,2 & 24,3 & 40,7 & 16,1 \\
\hline - Sin abuela ......................... & 11,0 & 12,4 & 9,9 & 14,3 & 11,6 & 11,0 \\
\hline - Con abuela ...................... & 3,2 & 59,7 & 26,3 & 10,1 & 29,1 & 5,1 \\
\hline 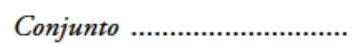 & 100,0 & 100,0 & 100,0 & 100,0 & 100,0 & 100,0 \\
\hline
\end{tabular}

FUENTE: Elaboración propia a partir de una muestra del 5 por 100 de hogares del Censo de 1991 (INE).

crece con la edad, de forma prácticamente ininterrumpida, en el caso de las solteras, o hasta alcanzar una estabilidad a partir aproximadamente de los cuarenta años, en el caso de las viudas y de las separadas. A partir de aproximadamente los sesenta ańos, vuelve a disminuir el porcentaje de núcleos solos. Las parejas siguen una pauta algo distinta: el porcentaje que no comparte el hogar con otras personas es netamente más alto en las edades más jóvenes y sigue creciendo hasta un máximo hacia los treinta años y después declina suavemente.

Existen, además, grandes diferencias entre los tipos de núcleos monoparentales, más acusadas en las edades jóvenes de las madres. Con la misma edad, las solteras son menos propensas a formar un hogar independiente, un indicador sin duda de la importancia de la ausencia de unión anterior. Las viudas y las separadas están muy próximas, siendo la proporción entre las primeras siempre superior (ver gráfico 1).

$\mathrm{La}$ importancia de la edad hace que las diferencias de estructura repercutan fuertemente sobre los datos globales. Las solteras, por ejemplo, más jóvenes, tienen más probabilidad de encontrarse todavía en el hogar paterno, simplemente porque son jóvenes. Si se comparan proporciones estandarizadas ${ }^{10}$, con el fin de eliminar la influencia de la estructura por edades, las diferencias se atenúan pero persisten. En particular, las solteras siguen siendo las que menos viven solas, aunque la proporción se acerca más a la media.

${ }^{10}$ La estandarización consiste en aplicar las proporciones por edad y tipo de núcleo a una estructura por edades común, que en este caso es la del conjunto de mujeres con hijo menor de 18 ańos. 


\section{GRÁFICO 1}

Proporción en hogares de un núcleo solo, según el tipo de núcleo y la edad. Madres con algún hijo menor de 18 años

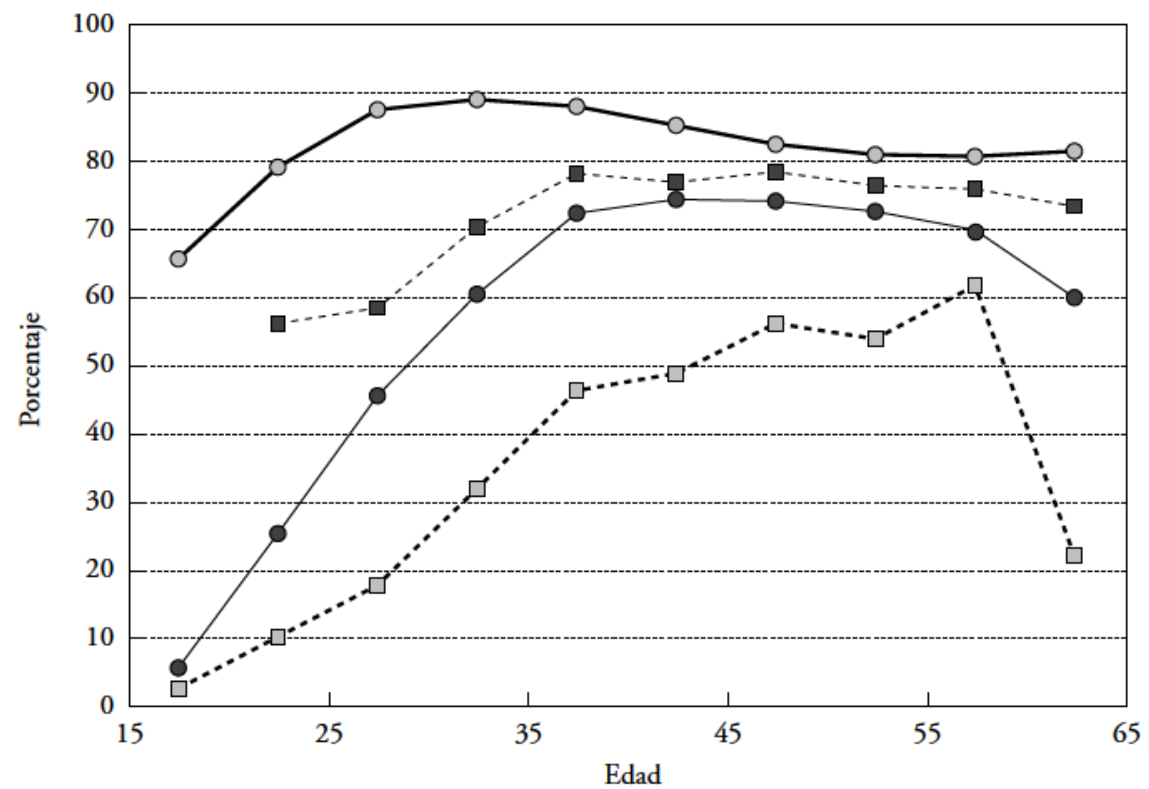

\section{$\neg$ - Pareja $\quad-\square-$ Soltera $\rightarrow-$ Separada - - - Viuda}

FUENTE: Elaboración propia a partir de una muestra del 5 por 100 de hogares del Censo de 1991 (INE).

Los núcleos que forman hogar con otras personas se encuentran en principio en mejores condiciones ${ }^{11}$ para afrontar el problema de la compatibilidad entre el trabajo y el cuidado de los nińos, para lo cual es sumamente importante el papel que desempeñan las abuelas ${ }^{12}$, que están permitiendo que un número creciente de mujeres trabaje, o por lo menos esté en el mercado de trabajo, como ponen de manifiesto nuestra investigación y varios trabajos recientes (ver, por ejemplo, Rodríguez y Sancho, 1995). En el caso de las monoparentales, el recurso a la abuela es bastante claro: casi el 30 por 100 de las madres sin pareja vive con su propia madre, y el porcentaje alcanza el doble de esta cifra entre las solteras. En contraste, son muy pocas (un 3 por 100) las parejas que

${ }^{11}$ Aunque no siempre es así, ya que los terceros pueden constituir cargas adicionales (padres mayores, por ejemplo) que agravan la situación de la madre monoparental. El Censo no permite dilucidar estas cuestiones.

${ }^{12}$ Se ha consagrado la palabra "abuela», en referencia al nińo más que a la madre. 
viven con la abuela (ver cuadro 4). De forma similar a lo comentado anteriormente, la eliminación del efecto de estructura por edad mantiene lo esencial de estas diferencias, aunque las atenúa.

La ayuda que las abuelas prestan a su hijas, sobre todo cuidando a los nietos, no exige la convivencia. En esta y en otras investigaciones (Tobío, Arteta y Fernández Cordón, 1996) ha quedado patente el carácter muy general de la ayuda de las abuelas, que frecuentemente viven cerca de sus hijos. No puede afirmarse, aunque es probable, que la intervención de la abuela sea más intensa en el caso de las familias monoparentales, pero sí que adopta modalidades distintas, al ser mucho más frecuente su presencia en el hogar. Esta situación tiene, sin duda, ventajas para la madre a la hora de hacer frente a sus cargas familiares al mismo tiempo que trabaja, pero también genera una serie de inconvenientes ligados a la convivencia, a veces impuesta por las circunstancias.

La proporción de monoparentales que forman su propio hogar, sin la presencia de otras personas, es todavía más reducida entre las que tienen a su cargo al menos un hijo menor de seis años, mientras que en el caso de las madres con pareja la edad del hijo menor no tiene prácticamente ninguna influencia. Sólo el 20 por 100 de las madres solteras con un hijo pequeño forman un hogar propio (frente al 28 por 100 del conjunto de solteras con hijo menor de 18 años) y el 52 por 100 de las separadas o divorciadas (frente al 64 por 100 del conjunto). La presencia de la abuela es también mayor en este grupo: el 70 por 100 de las solteras y casi el 40 por 100 de las separadas con hijo menor de seis años conviven con su madre (ver cuadro 5).

Tanto la autonomía de los núcleos monoparentales como la presencia de la abuela en el hogar forman parte de las estrategias que las mujeres desarrollan para poder atender sus cargas familiares mientras desempeñan un trabajo. En ellas inciden factores sociales y culturales que facilitan o, al contrario, dificultan la existencia de hogares más extensos. Prueba de ello son las diferencias que existen entre Comunidades Autónomas en España. En Andalucía es más frecuente el hogar compartido (menos del 56 por 100 de las familias monoparentales viven solas, frente al 63,5 por 100 en Cataluña), sobre todo entre las madres solteras (el 24 por 100 vive en un hogar sin otras personas, frente al 40 por 100 en Cataluña), pero también en las otras categorías de núcleo. La presencia de la abuela en el hogar varía también según la Comunidad Autónoma. El 66 por 100 de las madres solteras andaluzas tienen a su madre en casa, y sólo el 45 por 100 en el País Vasco o el 47 por 100 en Cataluña. Las diferencias se atenúan, pero persisten con claridad, cuando se elimina el efecto de las diferencias de estructura por edades entre Comunidades.

Esta diversidad plantea el problema general de las modalidades concretas de participación de las abuelas y de su viabilidad como instrumento de conciliación del trabajo y la familia. La convivencia es más fácil en las sociedades tradicionales, a la vez porque es mejor aceptada socialmente y porque las abuelas están más disponibles como amas de casa, al haberlo sido toda la vida. Si la situación en Comunidades como Cataluña prefigura lo que puede extenderse a toda España en un futuro no muy lejano, el recurso a las abuelas tenderá a disminuir, por los menos en su forma más directa de convivencia. 


\section{CUADRO 5}

Distribución de los núcleos familiares, según el tipo de núcleo y el tipo de hogar. España, 1991. Madres con algún hijo menor de 6 años (Tipo de hogar por cien de cada tipo de núcleo)

\begin{tabular}{|c|c|c|c|c|c|c|}
\hline \multirow[b]{3}{*}{ Tipo de hogar } & \multicolumn{5}{|c|}{ Tipo de núcleo } & \multirow[b]{3}{*}{ Total } \\
\hline & \multirow[b]{2}{*}{ Pareja } & \multicolumn{4}{|c|}{ Monoparentales } & \\
\hline & & Soltera & Separada & Viuda & Conjunto & \\
\hline Un núcleo solo ......................... & 87,3 & 20,2 & 52,6 & 69,2 & 41,6 & 84,8 \\
\hline Núcleo con otros ..................... & 12,7 & 79,8 & 47,4 & 30,8 & 58,4 & 15,2 \\
\hline - Sin abuela ........................ & 9,2 & 10,6 & 9,2 & 13,4 & 10,0 & 9,2 \\
\hline - Con abuela ....................... & 3,6 & 69,2 & 38,2 & 17,4 & 48,3 & 6,0 \\
\hline 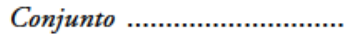 & 100,0 & 100,0 & 100,0 & 100,0 & 100,0 & 100,0 \\
\hline
\end{tabular}

FUENTE: Elaboración propia a partir de una muestra del 5 por 100 de hogares del Censo de 1991 (INE).

\section{LAS CARACTERISTICAS PRINCIPALES DE LAS MADRES MONOPARENTALES}

El Censo de Población de 1991 recoge las características básicas de los individuos y de los hogares, una información no muy extensa pero muy valiosa por su cobertura exhaustiva. La explotación de la muestra del 5 por 100 de hogares, sobre la que se basa este trabajo, se enfrenta con el problema de lo exiguo de la población estudiada, algo más de 450 mil personas, entre madres y padres monoparentales, lo que limita el número posible de cruces entre variables y el uso de técnicas que exijan una desagregación muy detallada de los datos.

Debido a estas limitaciones, se ha centrado el análisis fundamentalmente en las madres, que representan más del 85 por 100 del conjunto de monoparentales. Esta abrumadora mayoría les confiere una importancia mayor, como fenómeno social y como objeto de políticas sociales, y además contribuye a que los resultados del análisis sean estadísticamente mucho más significativos en su caso que en el de los padres.

\section{La edad: un indicador complejo}

La proporción de monoparentales en el total de núcleos con hijo a cargo muestra grandes diferencias según la edad del progenitor. El porcentaje de 
monoparentales es mayor entre los jóvenes y entre los mayores, con una distribución por edades en forma de U, cualquiera que sea el límite de edad fijado al hijo menor. Si éste es de 18 años, de acuerdo con la definición adoptada, la proporción de madres monoparentales, que es en promedio del 7,4 por 100, alcanza el 22,6 por 100 en el grupo de 15-19 y el 16,4 por 100 en el de 60-64 ańos, superando el 31 por 100 entre las madres de $65 \mathrm{y}$ más años. El peso de las madres sin pareja en los grupos más mayores aumenta cuando no se fija límite de edad al hijo menor, llegando a casi el 50 por 100 de las madres de 65 y más años.

Esta distribución es el resultado de la superposición de la distribución por edades de las madres solteras, que representan proporciones decrecientes con la edad (desde un 20 por 100 a los 15-19 hasta ser prácticamente nula después de los 40 años), y de la distribución de las viudas con hijo a cargo, creciente con la edad a partir de los 35-39, llegando a superar el 50 por 100 en las edades más altas. La presencia de monoparentales separadas es, por el contrario, más constante en todas las edades, con una ligera disminución a partir de 45-49 años (ver gráfico 2).

\section{GRÁFICO 2}

Proporción de monoparentales en el conjunto de madres con hijo menor de 18 años

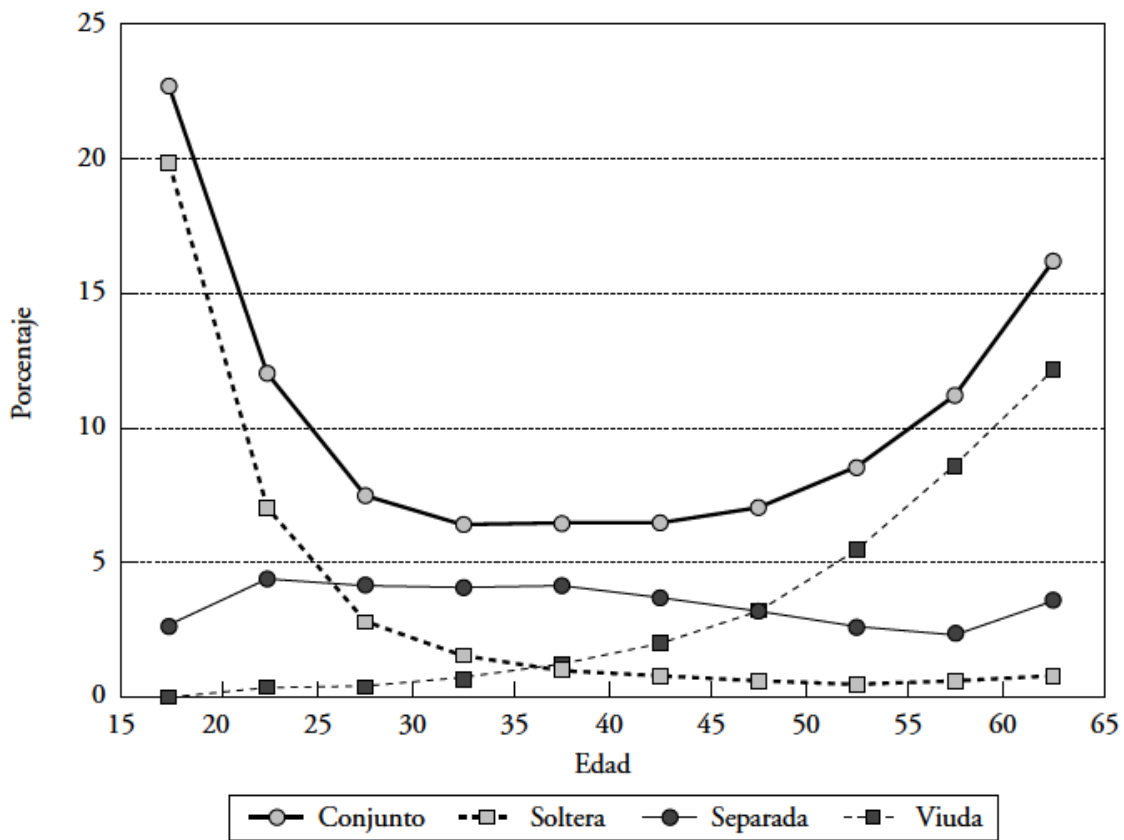

FuENTE: Elaboración propia a partir de una muestra del 5 por 100 de hogares del Censo de 1991 (INE). 
Aunque en el conjunto de monoparentales hay una mayoría de madres divorciadas o separadas, entre las más jóvenes dominan las solteras sin pareja, que representan el 90 por 100 de las madres monoparentales de 15-19 años y el 60 por 100 de las de 20-24 años. Algo similar ocurre en las edades más elevadas, en las que se concentran las viudas con hijo a cargo, que representan más del 70 por 100 desde los 55-59 años. Sólo en el grupo central (entre 30 y 45 años) existe un predominio de las divorciadas y separadas.

En la distribución por edad de cada colectivo interviene, como elemento perturbador del análisis, la muy desigual estructura por edades de las diferentes categorías de madres. Con la finalidad de eliminar esta influencia se han calculado las proporciones de monoparentales entre las mujeres sin pareja según su estado civil ${ }^{13}$ (gráfico 3). Estas proporciones son muy similares en las categorías de viuda y de separadas y divorciadas, en las que la existencia de hijo menor a

\section{GRÁFICO 3}

Proporción de madres con hijo menor de 18 años entre mujeres sin pareja

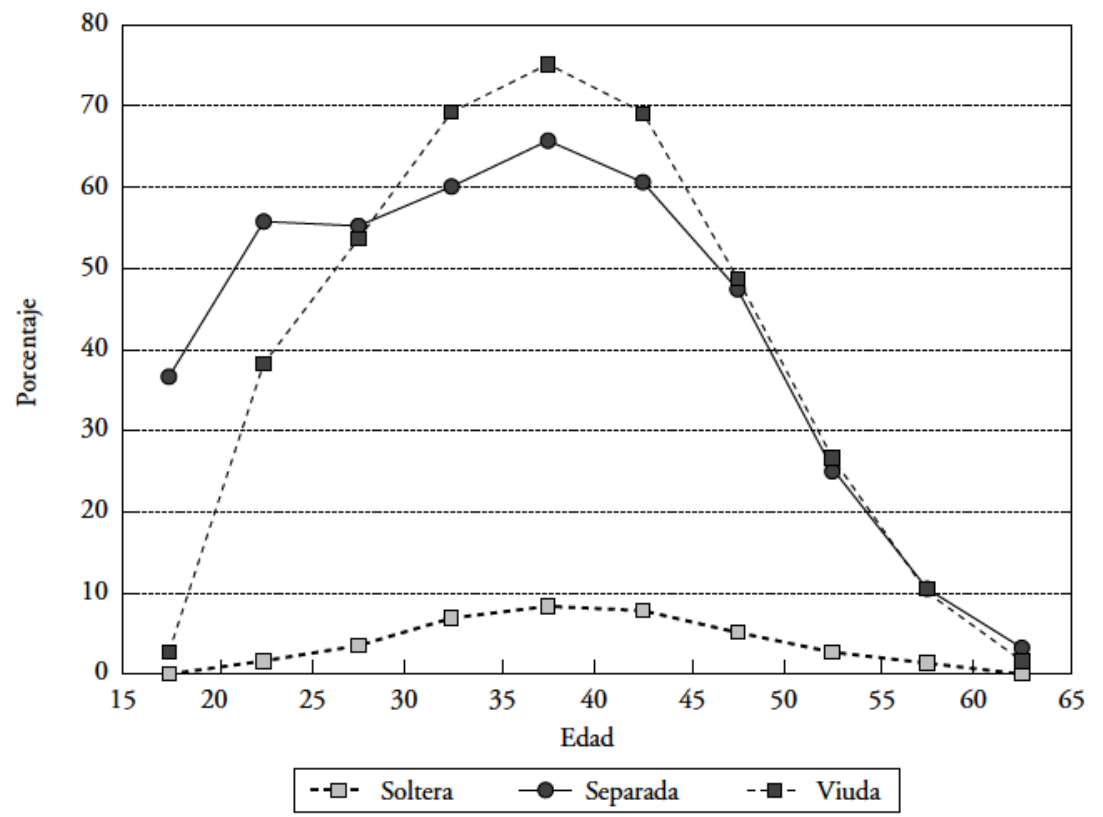

FUENTE: Elaboración propia a partir de una muestra del 5 por 100 de hogares del Censo de 1991 (INE).

${ }_{13}$ Por ejemplo, número de monoparentales divorciadas de una cierta edad entre las mujeres divorciadas de esa edad. 
cargo es muy frecuente a los 25-29 años y a los $45-49$ años: más del 50 por 100 de las viudas o de las separadas convive con un hijo menor de 18 años. La proporción aumenta con la edad, en los dos colectivos, hasta un máximo de 65,5 por 100 en las separadas y divorciadas y de 75,3 por 100 en las viudas, situado en ambos casos en el grupo 35-39 años. En el caso de las solteras, la proporción es mucho menor, superando apenas el 8 por 100 en el mismo grupo de edad.

Las diferencias observadas entre las viudas y las separadas provienen de diferencias entre las mujeres que sufren uno u otro tipo de ruptura. En primer lugar, para que una mujer figure como separada o divorciada debe pasar algún tiempo: el que exige el procedimiento judicial y también el de la propia gestación de la separación, que no es un proceso inmediato, por lo que, en realidad, la descendencia de una mujer separada corresponde a una edad anterior, y es por tanto inferior en promedio a la de una viuda de su misma edad, cuya unión se rompe de forma instantánea. Además, la separación o el divorcio no afectan por igual a todas las parejas, siendo más frecuente cuando la mujer cuenta con autonomía personal o tiene un mayor nivel de estudios, factores que están ligados entre sí y a una menor descendencia, aunque la hipótesis de que la probabilidad de divorciar esté negativamente relacionada con la presencia de hijos no se puede inferir de los datos manejados en este trabajo.

La elevada proporción con hijo menor a cargo entre mujeres que han sufrido una ruptura de unión indica que, en este caso, la monoparentalidad es una consecuencia indirecta del fin de la pareja y de las condiciones de la separación (en particular, la atribución habitual de la guarda de los hijos a la madre). La mayor o menor frecuencia del divorcio o la separación, así como de la viudez, son los factores significativos para analizar la monoparentalidad.

El caso de las monoparentales solteras es muy distinto. En ellas se mezclan los embarazos no deseados de adolescentes, un fenómeno preocupante en muchos países, y también en el nuestro (Delgado, 1994); las concepciones prenupciales y la maternidad que algunas mujeres deciden asumir voluntariamente al margen de una vida de pareja. Este último caso, aunque pueda ser el más llamativo, no es el más frecuente, y los demás constituyen con frecuencia etapas transitorias en las vidas de las mujeres afectadas, que acaban en su gran mayoría viviendo en pareja. También figuran como madres solteras las mujeres que han roto una unión de hecho, fenómeno todavía poco frecuente en España pero en auge.

\section{El nivel de estudios: un factor de heterogeneidad}

El 59 por 100 de las madres con algún hijo menor de 18 ańos tiene estudios primarios, el 34 por 100 ha cursado estudios secundarios y el 7,3 por 100 ha completado estudios superiores. Las madres monoparentales tienen, en promedio, un nivel de estudios algo más elevado: el 37,6 por 100 ha cursado estu- 
dios secundarios, situándose 4 puntos por encima de las que viven en pareja, y el 8,5 por 100 ha cursado estudios superiores, superando en más de un punto a las que tienen pareja (cuadro 6).

\section{CUADRO 6}

Distribución de las madres de 15 o más años, con algún hijo menor de 18 años, según tipo de núcleo y nivel de estudios. España, 1991

(Por cien en cada tipo de núcleo)

\begin{tabular}{|c|c|c|c|c|c|c|}
\hline \multirow[b]{3}{*}{ Nivel de estudios } & \multicolumn{5}{|c|}{ Tipo de núcleo } & \multirow[b]{3}{*}{ Total } \\
\hline & \multirow[b]{2}{*}{ Pareja } & \multicolumn{4}{|c|}{ Monoparentales } & \\
\hline & & Soltera & Separada & Viuda & Conjunto & \\
\hline Estudios primarios ............... & 59,2 & 48,6 & 44,6 & 76,2 & 53,8 & 58,8 \\
\hline Estudios secundarios ............... & 33,6 & 44,8 & 43,7 & 20,0 & 37,6 & 33,9 \\
\hline 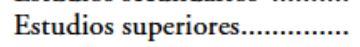 & 7,2 & 6,7 & 11,7 & 3,9 & 8,5 & 7,3 \\
\hline 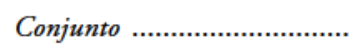 & 100,0 & 100,0 & 100,0 & 100,0 & 100,0 & 100,0 \\
\hline
\end{tabular}

FUENTE: Elaboración propia a partir de una muestra del 5 por 100 de hogares del Censo de 1991 (INE).

El grupo de las monoparentales dista de ser homogéneo: entre las viudas, las que sólo tienen estudios primarios tienen un peso muy superior $(76,2$ por 100) que el que se observa entre las solteras (48,6 por 100) o las separadas (44,6 por 100). Los niveles más altos se dan entre las separadas (un 43,7 por 100 con estudios secundarios y un 11,7 por 100 con estudios superiores), seguidas de las solteras (el 44,8 por 100 con estudios secundarios y un 6,7 por 100 con estudios superiores).

El nivel de estudios alcanzado puede considerarse desde dos puntos de vista. Por un lado, constituye un recurso que condiciona, entre otros, el acceso de las mujeres al mercado laboral, especialmente importante en el caso de las monoparentales. Por otro lado, puede tomarse como un indicador, aunque ciertamente imperfecto, del nivel social, sobre todo si se controlan las diferencias según la edad (que son, en realidad, diferencias entre generaciones).

Si se adopta el primer enfoque, las madres monoparentales están, por su mayor nivel educativo, en mejores condiciones que las madres con pareja para acceder al mercado de trabajo. Desde este punto de vista, puede afirmarse que el fenómeno de la monoparentalidad no está intrínsecamente ligado a un bajo estatus social. Ni siquiera las madres solteras constituyen un grupo especial- 
mente desfavorecido, puesto que su nivel de estudios es más elevado que el de las madres con pareja, es decir, de la mayoría de las mujeres. La situación social y económica de las madres monoparentales no es, por tanto, una consecuencia del escaso bagaje de las implicadas, sino más bien viene determinada por lo específico de su condición de mujeres sin pareja y con carga de hijos.

Analizar la influencia del nivel de estudios sobre la monoparentalidad es más delicado porque supone determinar si el nivel educativo (como aproximación del nivel social) está asociado, negativa o positivamente, a la monoparentalidad. No se pueden derivar fácilmente conclusiones directas porque las diferencias observadas están muy influidas por las importantes disparidades de estructura por edad de las madres según el tipo de núcleo, sobre todo en el caso de las solteras y de las viudas.

Hay que considerar que la proporción de mujeres que vive en pareja es sistemáticamente más elevada en el caso de las que tienen menor nivel de estudios y, a la inversa, la proporción de solteras y, sobre todo, de divorciadas es, en todas las edades, mayor entre las que tienen estudios superiores. Por otra parte, cualquiera que sea la situación de convivencia, la proporción de madres con hijo a cargo es siempre mayor entre las mujeres que tienen un menor nivel de estudios, aunque varía considerablemente según la situación de convivencia: siempre menor entre las mujeres separadas o divorciadas que entre las que viven en pareja.

Los datos globales, que son los que se manejan habitualmente, pueden conducir a conclusiones erróneas. La estructura por edades de las solteras, más jóvenes que las otras madres, lleva a subestimar la proporción de las que sólo tienen estudios primarios (más numerosas en las generaciones más antiguas) y de las que han cursado estudios superiores (jóvenes que no han terminado sus estudios). Lo contrario ocurre con las viudas, con un mayor peso de mujeres de más edad que tienen un nivel educativo bajo.

En resumen, hay que destacar la gran diferencia entre, por una parte, las monoparentales de ruptura, separadas, divorciadas y viudas, y las monoparentales directas que son las madres solteras. En las primeras, el evento desencadenante es la interrupción de la unión, cuya frecuencia está ligada negativamente al nivel social en el caso de la viudez (aunque no muy intensamente) y positivamente en el caso de la separación o divorcio, mientras que la proporción de viudas o de separadas que tienen hijo a cargo sigue pautas comunes, de carácter general. En el caso de las solteras, lo importante es el hecho de tener un hijo y las diferencias sociales se muestran, por tanto, con más claridad a ese nivel. Ser madre soltera sigue siendo mucho más frecuente entre las mujeres de más bajo nivel educativo. 


\section{LA PARTICIPACIÓN EN EL MERCADO DE TRABAJO DE LAS MADRES MONOPARENTALES}

\section{La actividad laboral: la lógica de la necesidad}

En conjunto, las mujeres en España tienen una tasa de participación baja, si se compara con el resto de los países de la Unión Europea, por ejemplo. En 1991 se declaraban activas 33 de cada cien mujeres de 16 o más años (INE, 1992), cuando la media europea rondaba el 40 por 100 (Eurostat, 1996). Actualmente, esta tasa se acerca progresivamente a los niveles medios europeos, siendo del 36 por 100 en 1996 (INE, 1997). Todos los países del Sur de Europa muestran niveles de participación próximos entre ellos e inferiores a los imperantes en el resto de la Unión Europea, especialmente a los del Norte, como Dinamarca, que, con un 60 por 100 de activas, se sitúa muy por encima del nivel español o italiano.

En torno al nivel medio del conjunto de mujeres se establecen diferencias muy sensibles según su situación familiar (ver cuadro 7). Como es bien sabido, las mujeres desempeñan una doble función: la tradicional, como ama de casa dedicada a las tareas domésticas, cuya responsabilidad siguen asumiendo bien mediante su realización material o su organización, y la más moderna y más valorada de trabajadora en el sistema productivo, opción cada vez más necesaria para la economía familiar. En los análisis de la actividad femenina se tiende a tomar como eje el imperativo familiar, concebido como un freno al deseo de trabajar de las mujeres, al que pueden acabar renunciando si las cargas familiares son excesivas. Las monoparentales plantean una situación inversa, al situar en el centro del problema la necesidad de trabajar que obliga a buscar una adaptación del entorno familiar. Este cambio de perspectiva, ahora manifiesto sólo en ciertas categorías de mujeres, puede llegar a imponerse al conjunto de ellas, en la medida en que el aumento de su participación en el mercado de trabajo se rige cada vez más por criterios de racionalidad económica, tanto en el plano colectivo de la sociedad o de las empresas como en el privado de la familia, cuya economía tiende a estar basada en la existencia de dos perceptores. De ahí que el estudio de la actividad de las madres monoparentales presente un interés añadido como modelo emergente de comportamiento del conjunto de las mujeres.

El primer factor de diferenciación que aparece en los datos manejados es la existencia o no de pareja. Las mujeres que carecen de pareja, con o sin hijos, tienen tasas de actividad por encima de las otras a todas las edades. Es imposible, con los datos disponibles, aislar en esta correlación el papel de la aportación económica de la pareja, ya que las mujeres que carecen de ella están a la vez mejor cualificadas y más orientadas al trabajo. Su comportamiento se asemeja al del hombre y, en ese sentido, obedecen a lo que podríamos llamar la lógica de la necesidad frente a lo que sería todavía una lógica de la elección en el caso de las mujeres con pareja. 


\section{CUADRO 7}

Tasas de actividad por edad de mujeres, según su situación de convivencia y la edad del hijo menor. España, 1991 (Activas por cien mujeres de cada grupo de edad)

\begin{tabular}{|c|c|c|c|c|c|c|c|c|c|}
\hline \multirow[b]{3}{*}{ Edad del progenitor } & \multirow[b]{3}{*}{$\begin{array}{c}\text { Cojunto } \\
\text { de mujeres }\end{array}$} & \multicolumn{4}{|c|}{ Con pareja } & \multicolumn{4}{|c|}{ Sin pareja } \\
\hline & & \multirow[b]{2}{*}{$\begin{array}{l}\text { Conjunto } \\
\text { con pareja }\end{array}$} & \multicolumn{3}{|c|}{ Madres (edad del hijo menor) } & \multirow[b]{2}{*}{$\begin{array}{l}\text { Conjunto } \\
\text { sin pareja }\end{array}$} & \multicolumn{3}{|c|}{ Madres (edad del hijo menor) } \\
\hline & & & $<18$ años & $<6$ años & $\begin{array}{c}\text { Cualquier } \\
\text { edad }\end{array}$ & & $<18$ años & $<6$ años & $\begin{array}{c}\text { Cualquier } \\
\text { edad }\end{array}$ \\
\hline 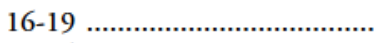 & 28,7 & 36,1 & 27,8 & 27,5 & 27,9 & 28,4 & 56,3 & 56,0 & 56,3 \\
\hline 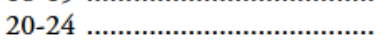 & 57,5 & 48,7 & 36,5 & 36,1 & 36,5 & 60,0 & 68,8 & 67,7 & 68,8 \\
\hline 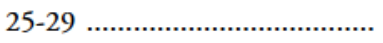 & 64,4 & 52,7 & 43,7 & 43,3 & 43,7 & 81,2 & 76,2 & 72,7 & 76,2 \\
\hline 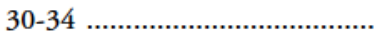 & 56,8 & 49,9 & 47,2 & 49,0 & 47,2 & 82,4 & 78,3 & 74,5 & 78,2 \\
\hline 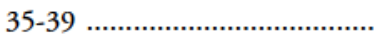 & 47,9 & 42,2 & 41,1 & 42,8 & 41,2 & 78,3 & 75,2 & 74,2 & 75,2 \\
\hline $40-44$................................. & 38,9 & 33,2 & 32,4 & 32,3 & 32,5 & 71,0 & 66,1 & 62,1 & 65,8 \\
\hline 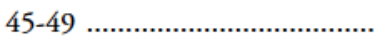 & 32,2 & 26,8 & 25,7 & 24,1 & 26,0 & 62,0 & 53,6 & 53,4 & 53,5 \\
\hline 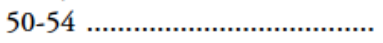 & 26,0 & 21,3 & 20,7 & 22,8 & 20,6 & 49,1 & 36,7 & 50,2 & 38,7 \\
\hline 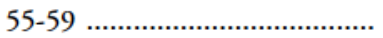 & 21,8 & 17,2 & 17,0 & 21,4 & 16,4 & 38,3 & 27,2 & 49,8 & 26,9 \\
\hline 60-64 & 15,5 & 12,1 & 13,9 & 21,6 & 12,1 & 23,7 & 21,2 & 15,8 & 16,9 \\
\hline 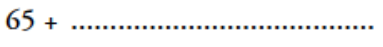 & 1,5 & 1,8 & 12,6 & 24,6 & 2,6 & 1,3 & 9,8 & 7,2 & 1,6 \\
\hline TOTAL & 33,3 & 29,4 & 36,8 & 43,2 & 31,2 & 38,8 & 64,9 & 69,9 & 35,7 \\
\hline
\end{tabular}

FUENTE: Elaboración propia a partir de una muestra del 5 por 100 de hogares del Censo de 1991 (INE). 
La importancia de la pareja aparece también al considerar el otro factor de diferenciación que son los hijos, cuya presencia se asocia con una menor tasa de actividad, a todas las edades, tanto en las mujeres con pareja como en las que no la tienen. Sin embargo, el efecto es mayor en las que tienen pareja, sobre todo entre las jóvenes, que apenas se ven afectadas por la presencia de hijos, cuando no tienen pareja. Hasta los 30-34 años, las mujeres se dividen en dos grupos muy contrastados: las casadas con hijo, cuya participación es inferior al 40 por 100 , y el resto, las que viven en pareja sin hijo y las que viven sin pareja, sin hijo o con hijo (monoparentales), que se acercan al 80 por 100 . Sólo por encima de cuarenta años se aprecia con más fuerza el efecto negativo de la presencia de hijos entre las mujeres que carecen de pareja.

El resultado es una mayor presencia en el mercado laboral de las mujeres monoparentales en relación a las madres con pareja y al conjunto de las mujeres (ver gráfico 4).

\section{GRÁFICO 4}

Tasas de actividad por edad y tipo de núcleo. Madres con algún hijo menor de 18 años. España, 1991

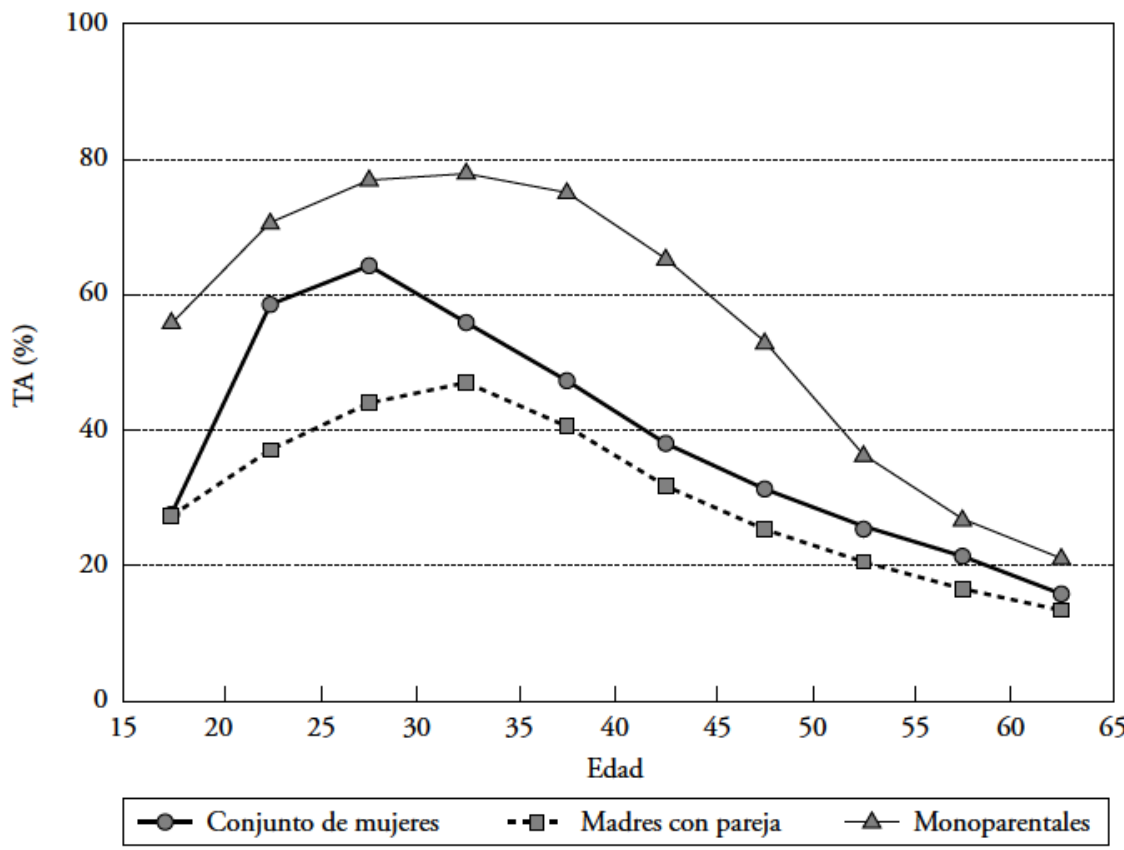

FUENTE: elaboración propia a partir de una muestra del 5 por 100 de hogares del Censo de 1991 (INE). 
En el seno de las monoparentales existe una diferenciación muy neta entre, de una parte, las viudas $y$, de otra, las solteras y las separadas. Las viudas tienen, a todas las edades, tasas de actividad próximas a las de las mujeres con pareja, aunque algo más elevadas en las más jóvenes, edades en que las viudas son poco numerosas y los datos no demasiado significativos. Las tasas más altas se dan en las solteras, sobre todo a partir de los cuarenta años. Estas dos observaciones ratifican la importancia de la situación de pareja en el nivel de la tasa de actividad de las mujeres. Por ejemplo, en el caso de las viudas, la muerte del cónyuge no hace desaparecer del todo su aportación económica (que sigue llegando en forma de pensión de viudedad y de herencia, salvo precisamente en las más jóvenes). Lo mismo ocurre con las separadas, sobre todo las de más edad, aunque no con la misma certidumbre que en el caso de las viudas.

En general, las diferencias son más acusadas en las mujeres mayores. A los efectos de generación, que se aprecian en todas las mujeres, se une el que la ruptura de la pareja se ha podido producir a mayor edad, lo que dificulta, por tardío, el acceso al mercado de trabajo.

El número de hijos afecta negativamente a la participación en la actividad de las monoparentales, aunque su efecto es moderado, y siempre menor que en el caso de las madres con pareja. La tasa de actividad varía entre el 76 por 100 , en las que tienen un único hijo, al 60 por 100, en las que tienen cuatro o más hijos, todavía muy por encima de la tasa de las madres con pareja con un solo hijo (49 por 100). El mayor salto se da entre las que tienen uno y las que tienen más de uno, sobre todo en el caso de las solteras. Los resultados son muy parecidos si consideramos únicamente las madres con algún hijo menor de seis ańos. El efecto negativo sobre la actividad del número de hijos se ejerce sobre todas las mujeres, pero con más intensidad entre las que tienen pareja.

Como es sabido, el nivel de estudios influye directamente sobre las tasas de actividad, tanto más elevadas cuanto más alto es el nivel. Son activas el 27 por 100 de las madres con hijo menor de 18 años que tienen sólo estudios primarios, casi el 50 por 100 de las que han cursado estudios secundarios y el 82 por 100 de las que tienen estudios superiores.

Esta relación se verifica tanto en las madres con pareja como en las monoparentales y, en el caso de estas últimas, cualquiera que sea su estado civil. Al ser las tasas de las madres monoparentales en promedio más elevadas, las diferencias por nivel de estudios son también más reducidas, con tasas de actividad que varían del 53 por 100 entre las que tienen estudios primarios al 89 por 100 entre las que han cursado estudios superiores. Si tomamos las solteras, el abanico es aún más estrecho: del 71,4 al 90 por 100, respectivamente.

Entre todos los grupos que se pueden formar combinando la situación familiar y el nivel de estudios, el abanico es muy abierto: de las mujeres con pareja que tienen estudios primarios sólo un 26 por 100 son activas, mientras que entre las solteras o separadas con estudios superiores se llega al 90 por 100 de activas.

El gráfico 5, que presenta las tasas de actividad por edades, muestra la 
doble determinación: la convivencia con pareja, asociada a tasas de actividad reducidas, y el nivel de estudios, que actúa en sentido contrario. Las madres con pareja que han cursado estudios superiores tienen un nivel de participación más alto que las que sólo tienen estudios primarios, pero son superadas por las monoparentales, incluso por las de menor nivel educativo (al menos hasta los 55 años). Frente al nivel de estudios alcanzado, que es una característica individual de las mujeres, se impone su situación familiar como determinante básico de la participación en el mercado de trabajo.

\section{GRÁFICO 5}

Tasas de actividad por nivel de estudios. Madres con algún hijo menor de 18 años

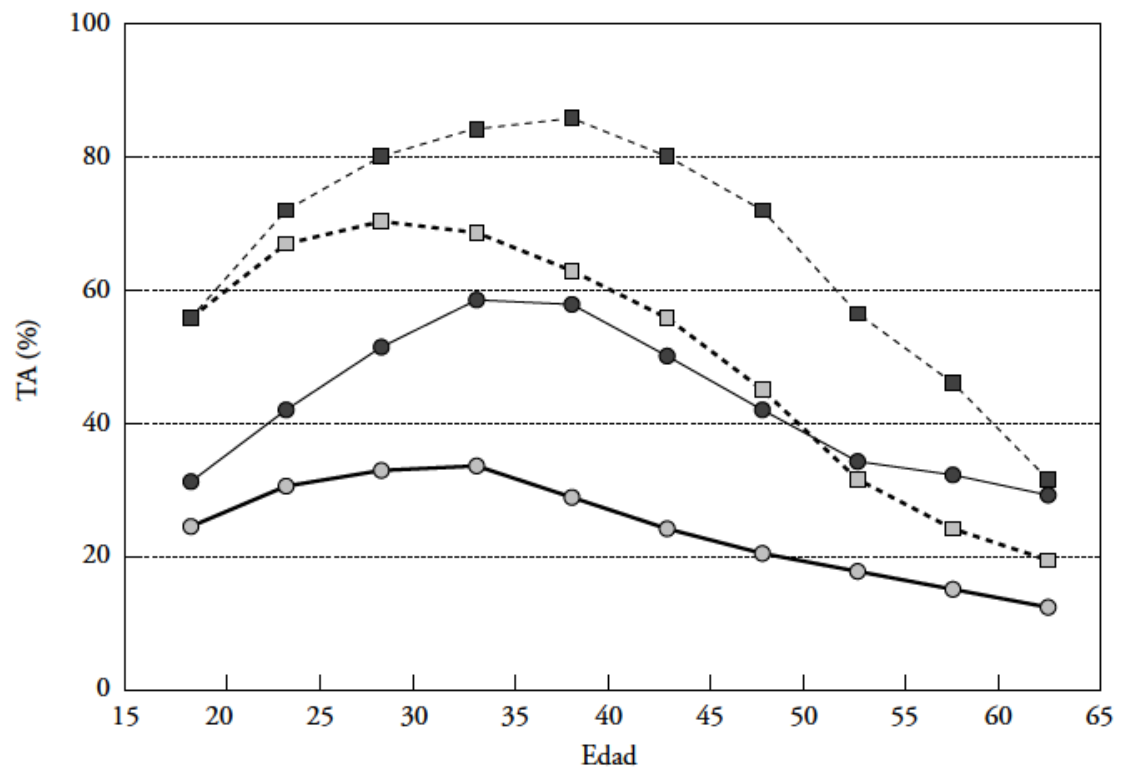

$\begin{array}{lll}\rightarrow-\text { Pareja - Primarios } & -\square- & \text { Monoparental - Primarios } \\ -0-\text { Pareja - Sec. o Sup. } & -\square- & \text { Monoparental - Sec. o Sup. }\end{array}$

FUENTE: Elaboración propia a partir de una muestra del 5 por 100 de hogares del Censo de 1991 (INE).

La fuerte incidencia de la edad en el nivel de participación y las grandes diferencias de estructura por edades que separan a las categorías de núcleo generan diferencias sólo atribuibles al efecto de estructura. $\mathrm{Si}$ se elimina este efecto, mediante estandarización de las tasas, desaparece en las solteras la clara relación entre nivel de estudios y participación. En esta categoría actúa como 
factor principal la condición de madre soltera, siendo su nivel de participación relativamente independiente del nivel de estudios.

\section{El paro: menor influencia de la situación familiar}

Las tasas de actividad no miden la ocupación real porque incluyen a las que se encuentran en paro en el momento de referencia. El paro es un concepto difícil de medir (lo que da pie a alguna que otra polémica) porque supone comprobar la conjunción de una serie de elementos, algunos de los cuales no tienen un carácter objetivo indiscutible. No haber trabajado durante la semana anterior, estar activamente buscando trabajo y estar disponible para ocupar un puesto de trabajo son las principales condiciones para que una persona pueda ser contada como parada ${ }^{14}$.

La convivencia con pareja incide mucho menos en la tasa de paro que en la tasa de actividad, siendo entre las mujeres con pareja algo inferior a la que experimentan las monoparentales (el 25,5 frente al 28,3 por 100). Es más importante, aunque no determinante, la presencia de hijos, puesto que todas las mujeres jóvenes con hijos tienen tasas de paro más elevadas, vivan o no en pareja. Las madres con pareja, con hijo menor de 18 años, no se distinguen prácticamente de las monoparentales, con una tasa de paro superior a la del conjunto de mujeres hasta los 35 años aproximadamente.

Lo anterior no impide que, en conjunto y debido a las diferencias de estructura por edades de los grupos, la tasa de paro de las madres solteras $(38,5$ por 100$)$ sea superior a la de las separadas $(26,4$ por 100$)$ y a la de las madres con pareja $(25,6$ por 100$)$. La estandarización de las tasas reduce estas diferencias y sólo persiste un paro algo mayor entre las solteras con hijo.

La relación positiva entre paro y presencia de hijo puede ser el resultado de un factor común, el bajo nivel de estudios por ejemplo, que esté asociado de la misma manera a los dos fenómenos: a menor nivel de estudios, más hijos y menores oportunidades de encontrar trabajo. Los hijos también actúan como obstáculo para encontrar trabajo, e incluso tampoco se puede descartar que el paro constituya una forma extrema de sacar tiempo para el cuidado de los hijos.

En relación al nivel de estudios, la tasa de paro sigue una pauta inversa a la observada en el caso de la actividad: la más elevada se da entre las que sólo tienen estudios primarios y la menor entre las que han cursado estudios superiores. En el conjunto de madres con hijo menor de 18 ańos, la tasa de paro es tres veces más elevada entre las que sólo tienen estudios primarios que entre las que tienen estudios superiores ( 29,6 y 11,4 por 100 , respectivamente). El paro

${ }_{14}$ Todos estos conceptos están definidos con mucha precisión tanto en el Censo como en la EPA y se ajustan en general a recomendaciones de Organismos Internacionales, como la OIT, en este caso. 
es algo mayor entre las madres monoparentales a todas las edades (gráfico 6), pero, debido en buena parte al efecto de la estructura por edades, hay mucha diferencia según el tipo de núcleo: el paro de las de menor nivel de estudios es del 42,4 por 100 si son solteras con hijo y del 20,8 por 100 si son viudas. El paro de las madres solteras con estudios superiores (17,2 por 100) es casi del mismo nivel que el de las viudas con estudios primarios (20,8 por 100$)$. La diferenciación que introduce el nivel de estudios actúa también de forma diversa según el tipo de núcleo.

La estandarización de las tasas de paro muestra más claramente cómo se combinan la situación familiar y el nivel de estudios en la incidencia del paro, en un continuo que va desde el máximo de la madre soltera con estudios primarios hasta el mínimo de la viuda con estudios superiores.

\section{GRÁFICO 6}

Tasas de paro por nivel de estudios. Madres con algún hijo menor de 18 años

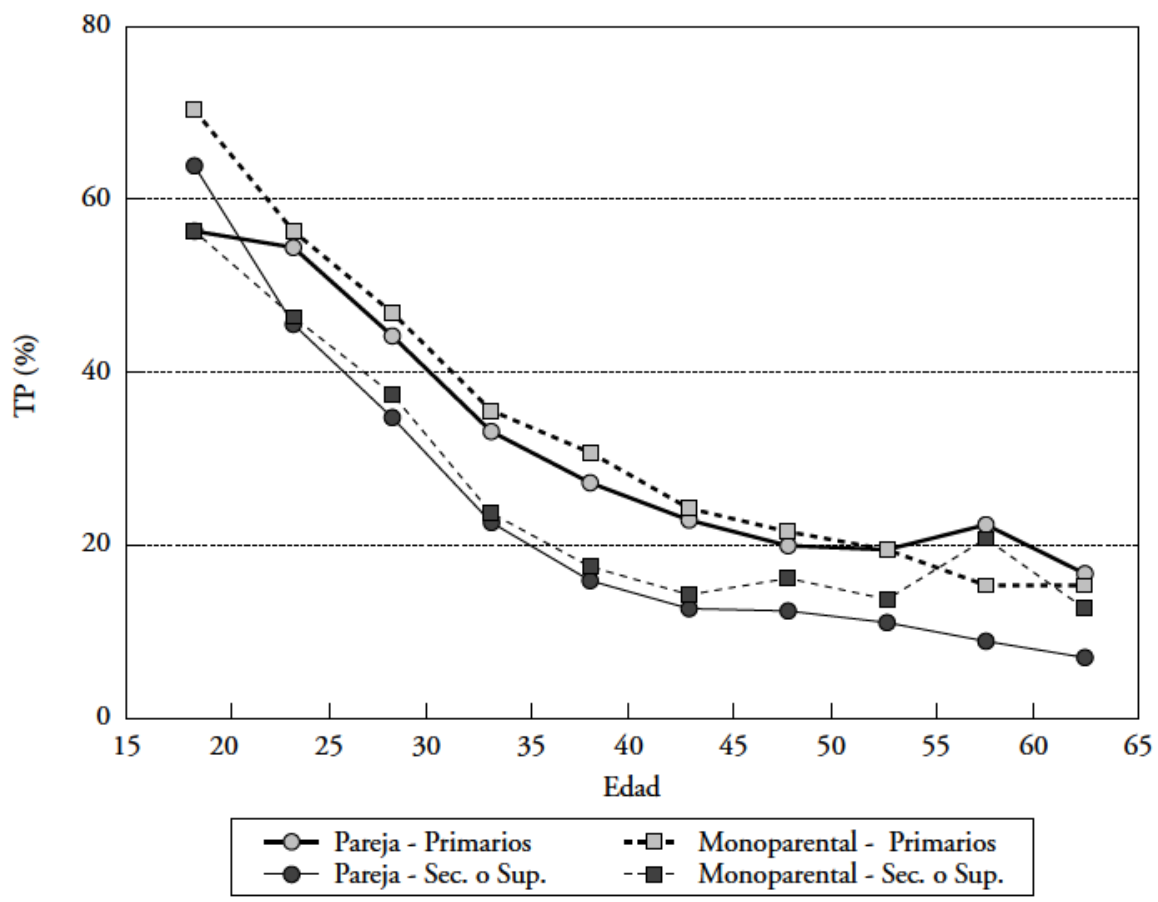

FUENTE: Elaboración propia a partir de una muestra del 5 por 100 de hogares del Censo de 1991 (INE). 


\section{CONCLUSIÓN}

Aunque lo que hoy llamamos familias monoparentales han existido siempre, incluso con una incidencia superior en el siglo pasado, la situación actual presenta rasgos específicos, en lo relativo a la composición interna de esta categoría de familia y a la consideración social que se le atribuye. En nuestros días, la mayoría de las madres y de los padres sin pareja la forman los divorciados y separados, mientras que anteriormente dominaban las viudas. También se ha producido un cambio importante en la percepción social, que antes separaba claramente a las viudas, tratadas con respeto, de las madres solteras, que eran objeto de rechazo. La unificación de estas situaciones en un concepto único ha desplazado el interés hacia el problema que plantea la carga de hijos menores no compartida con una pareja. Hoy preocupa sobre todo la mayor vulnerabilidad social de los componentes de este tipo de familia, y más concretamente la situación de las madres, que deben compaginar, en condiciones especialmente difíciles, la necesidad de trabajar y la obligación de cuidar de sus hijos.

En los últimos años, la proporción de familias monoparentales en España se ha incrementado muy moderadamente y puede todavía considerarse como muy reducida, si se compara con los otros países de la Unión Europea, especialmente con los escandinavos. Lo más notable de la evolución reciente es el peso creciente de las madres separadas y divorciadas, y en menor medida de las solteras, frente al declive de las viudas.

El número anual de divorcios aumenta muy moderadamente en nuestro país y su incidencia es muy pequeña, como lo es también en otros países del Sur de Europa. En el futuro, un aumento de la frecuencia del divorcio, que puede considerarse previsible habida cuenta de nuestro creciente acercamiento a los comportamientos que se observan en el resto de los países de Europa, conducirá sin duda a un incremento del número de monoparentales.

El número de madres solteras depende de la capacidad de evitar nacimientos no deseados, sobre todo entre adolescentes y jóvenes, o sea, del conocimiento y uso de los anticonceptivos y del recurso a la interrupción voluntaria del embarazo, y también de la importancia de las rupturas de parejas de hecho, fenómeno todavía poco frecuente y mal conocido, pero cuya incidencia se estima que irá en aumento. La monoparentalidad de las solteras está también íntimamente ligada a la nueva dinámica de formación de las familias y a la emergencia de nuevas formas familiares, tales como las parejas de hecho y las familias reconstituidas, que ponen fin a una situación de monoparentalidad.

Todo apunta, por consiguiente, a que la unificación de situaciones diversas en un concepto único, cuya utilidad histórica ya se ha señalado, deba ser actualmente cuestionada, ante la diversidad de las trayectorias que conducen a la monoparentalidad y la diversidad de situaciones que afrontan las mujeres, según que trabajen o no o que cuenten o no con ayuda en su hogar. 


\section{BIBLIOGRAFÍA}

Almeda, E., y Flaquer, L. (1995): "Las familias monoparentales en España: un enfoque crítico", en Revista Internacional de Sociología, tercera época, n. ${ }^{\circ} 11$, pp. 21-45.

Arenas MartíneZ, M. (1996): Las familias de madres solas en Avilés, Dirección General de la Mujer, Consejería de Servicios Sociales del Principado de Asturias.

Bank, L.; Forgatch, M. S.; Patterson, G. R., y Fetrow, R. A. (1993): «Parenting practices of single mothers: mediators of negative contextual factors", en Journal of Marriage and the Family, vol. 55, 2, pp. 371-384.

BILARZ, T. J., y RAFTERY, A. E.: "The effects of family disruption on social mobility", en American Sociological Review, vol. 58, 1, pp. 97-109.

Delgado PÉREZ, M. (1994): La fecundidad de las adolescentes, CIS, Madrid.

Dronkers, J. (1994): "The Changing effects of Lone Parent Families on the Educational Attainment in a European Welfare State", en Sociology, 28, 1, pp. 171-191.

Duncan, G.; Yeung, J. W., y Rodgers, W. (1994): "Les familles monoparentales aux ÉtatsUnis. Dynamique, niveau de vie et conséquences sur le developpement de l'enfant", en Population, 6, 1419-1436.

DURAN, M. A. (1988): "Hogares y familias: dos conceptos en busca de definición», en J. IGLESIAS DE USSEL, Las familias monoparentales en España, MAS, Madrid.

European Observatory on National Family Policies (1996): Policy and the Employment of Lone Parents in 20 Countries, The University of York.

Eurostat (1996): Statistiques démographiques 1996, Luxemburgo.

FERNÁNDEZ CORDÓN, J. A (1997): "Youth residencial independence and autonomy. A comparative study", en Journal of Family Issues (6).

FERnÁNDEZ CORDÓN, J. A., y Tobfo, C. (1997): Las familias monoparentales en España, Informe de la investigación realizada mediante convenio entre la Universidad Carlos III de Madrid y el Ministerio de Asuntos Sociales.

FESTY, P. (1988): "Apres la separation: diversité et stabilité des comportements", en Population, 3.

LE GALL, D., y MARTIN, C. (1987): Les familles monoparentales. Evolution et traitement social, Les Editions ESF, París.

HeRnÁdeZ Rodrf́guez (1996): Situación económica das mulleres separadas en Galicia, Xunta de Galicia.

IGLESIAS DE UsSEL, J. (1988): Las familias monoparentales, Instituto de la Mujer, Ministerio de Asuntos Sociales, Madrid.

- (1998): La familia y el cambio politico en España, Tecnos, Madrid.

INE (1990): Censos de Población y Viviendas 1991 - Proyecto, Madrid.

- (varios ańos): Encuesta de Población Activa - Medias anuales, Madrid.

INSEE (1994): Les familles monoparentales, París.

JudGE, K., y BENCEVAL, M. (1993): "Health inequalities: new concerns about the children of single mothers", en British Medical Journal, vol. 306, 6879, pp. 677-680.

KiERnAN, K. E. (1992): "The Impact of Family Disruption in Childhood on Transitions Made in Young Adult Life», en Population Studies, 46, 2, pp. 213-234.

KNIBIEHLER, Y. (1993): «Un éternel recommencement?», en Autrement, 134, pp. 18-26.

MARTIN, C. (1994): "Diversité des trajectoires post-union. Entre le risque de solitude, la defense de son autonomie et la recomposition familiale», en Population, 6, pp. 1557-1583.

MINISTERIO DE ASUNTOS SOCIALES (1995): Informe sobre las familias monoparentales, Madrid.

NeYrand, G. (1990): "L'education des enfants de parants isolés», en Savoir Education Formation, 3, pp. 455-466.

Rankin, J. H., y KeRn, R. (1994): "Parental attachments and delinquency", en Criminology, vol. 32, 4, pp. 495-515.

Reher, D. (1997): La familia en España. Pasado y presente, Alianza Universidad, Madrid.

Rodriguez Rodrfguez, P., y SANCho CASTIEllo, M. T. (1995): «Vejez y familia: apuntes sobre una contribución desconocida", en Infancia y Sociedad, n. ${ }^{\circ} 29$, pp. 63-78. 
Roll, J. (1992a): «Familias Monoparentales en Europa», en Infancia y Sociedad, 16.

- (1992b): Lone Parent Families in the European Community. A Report to the European Commission, European Family and Social Policy Unit.

Thomson, E.; Hanson, T. L., y MCLANAHAN, S. S. (1994): «Family structure and family wellbeing: economic resources vs. parental behaviors», en Social Forces, vol. 73, 1, pp. 221-242.

Tobí, C.; ARTETA, E., y Fernández CORdÓN, J. A. (1996): Estrategias de compatibilización familia-empleo. España, años noventa, Universidad Carlos III de Madrid - Instituto de la Mujer.

Webster, P. S.; Orbuch, T. L., y House, J. S. (1995): «Effects of childhood family background on adult marital quality and perceived stability", en American Journal of Sociology, vol. 101, 2, 404-432.

\begin{abstract}
Lone parenthood is an imprecise concept including very different situations as widowhood, single parenthood and divorce. What is common to the three of them is that only one of the parents bears the load of the children. The exact meaning of these two aspects needs to be clarified. The article presents the analysis of lone parenthood in Spain based on data from the Census of Population of 1991 and the Labour Force Surveys of 1991 and 1996 according to comparative criteria used in most European countries. New data on lone parent families and households are produced and discussed as well data as on the main characteristics of lone mothers (age, eduction, employment and unemployment).
\end{abstract}

